\title{
CRISPR EnAbled Trackable genome Engineering for isopropanol production in Escherichia coli
}

Liya Liang ${ }^{\mathrm{a}}$, Rongming Liu ${ }^{\mathrm{a}}$, Andrew D. Garst ${ }^{\mathrm{b}}$, Thomas Lee ${ }^{\mathrm{c}}$, Violeta Sànchez i Noguéd ${ }^{\mathrm{d}}$, Gregg T. Beckham ${ }^{d}$, Ryan T. Gill ${ }^{a^{*}}$

${ }^{a}$ Renewable and Sustainable Energy Institute (RASEI), University of Colorado Boulder, Boulder, Colorado 80303, United States

b Muse Biotechnology Inc., 4001 Discovery Dr., Boulder, Colorado 80303, United States

${ }^{\mathrm{c}}$ Department of Chemistry and Biochemistry, University of Colorado Boulder, Boulder, Colorado 80309 United States

${ }^{d}$ National Bioenergy Center, National Renewable Energy Laboratory, Golden, Colorado 80401, United States

\begin{abstract}
Isopropanol is an important target molecule for sustainable production of fuels and chemicals. Increases in DNA synthesis and synthetic biology capabilities have resulted in the development of a range of new strategies for the more rapid design, construction, and testing of production strains. Here, we report on the use of such capabilities to construct and test 903 different variants of the isopropanol production pathway in Escherichia coli. We first constructed variants to explore the effect of codon optimization, copy number, and translation initiation rates on isopropanol production. The best strain (PA06) produced isopropanol at titers of $17.5 \mathrm{~g} / \mathrm{L}$, with a 1
\end{abstract}

(C) 2016. This manuscript version is made available under the Elsevier user license http://www.elsevier.com/open-access/userlicense/1.0/ 
yield of $0.62(\mathrm{~mol} / \mathrm{mol})$, and maximum productivity of $0.40 \mathrm{~g} / \mathrm{L} / \mathrm{h}$. We next integrated the isopropanol synthetic pathway into the genome and then used the CRISPR EnAbled Trackable genome Engineering (CREATE) strategy to generate an additional 640 individual RBS library variants for further evaluation. After testing each of these variants, we constructed a combinatorial library containing 256 total variants from four different RBS levels for each gene. The best producing variant, PA14, produced isopropanol at titers of $7.1 \mathrm{~g} / \mathrm{L}$ at $24 \mathrm{~h}$, with a yield of $0.75(\mathrm{~mol} / \mathrm{mol}$ ), and maximum productivity of $0.62 \mathrm{~g} / \mathrm{L} / \mathrm{h}$ (which was $0.22 \mathrm{~g} / \mathrm{L} / \mathrm{h}$ above the parent strain PA07). We demonstrate the ability to rapidly construct and test close to $\sim 1000$ designer strains and identify superior performers.

Keywords: Isopropanol; CRISPR EnAbled Trackable genome Engineering; RBS library; Engineered Escherichia coli; Proteomic analysis

\section{Introduction}

The sustainable production of fuels and other chemicals is of continued importance in light of increasing concerns about climate change and energy security (Ragauskas et al., 2006; Stephanopoulos, 2007; Tuck et al., 2012). Isopropanol is one of the secondary alcohols that can be produced by microbes (Osburn et al., 1937) and can be used instead of methanol to esterify fat and oil to produce biodiesel, which reduces the tendency to crystallize at low temperatures (Lee et al., 1995). Several species of Clostridium have been evaluated for isopropanol production. However, the maximum production of isopropanol from these strains was limited to $2.4 \mathrm{~g} / \mathrm{L}$ (Survase et al., 2011). Current interest in the development of alternative organisms for the 
industrial production of isopropanol has increased, as evidenced by the construction of genetically engineered Escherichia coli and yeast strains (Hanai et al., 2007; Inokuma et al., 2010; Jojima et al., 2008).

Hanai et al. engineered E. coli with the four enzymes acetyl-coenzyme A (CoA) acetyltransferase, acetoacetyl-CoA transferase, acetoacetate decarboxylase, and primarysecondary alcohol dehydrogenase (encoded by $t h l$, atoDA, $a d c$, and $a d h$ ) to produce $4.9 \mathrm{~g} / \mathrm{L}$ of isopropanol from glucose with a yield of $43 \%$ (mol $/ \mathrm{mol}$ ) (Hanai et al., 2007). Inokuma et al. used $\mathrm{pH}$ control and gas stripping to enhance the isopropanol production to $143 \mathrm{~g} / \mathrm{L}$ after $240 \mathrm{~h}$ with a yield of $67.4 \%$ (mol/mol) (Inokuma et al., 2010). Jojima et al. used the $\operatorname{ctfAB}$ gene for the acetoacetyl-CoA transferase resulting in $14 \mathrm{~g} / \mathrm{L}$ of isopropanol from glucose with a yield of $51 \%$ (mol/mol) (Jojima et al., 2008). Tamakawa et al. reported a genetically engineered strain of the yeast Candida utilis that produced $9.5 \mathrm{~g} / \mathrm{L}$ of isopropanol in batch and $27.2 \mathrm{~g} / \mathrm{L}$ in fed-batch fermentations (Tamakawa et al., 2013).

Advances in metabolic engineering, synthetic biology, and systems biology have provided a number of strategies for the more rapid design, construction, and testing of production strains (Endy, 2005; Stephanopoulos, 2012; Wang et al., 2009; Warner et al., 2010; Yadav et al., 2012). As one example, Multiplex Automated Genomic Engineering (MAGE) can simultaneously target many locations on the chromosome for modification, resulting in the generation of billions of combinatorial variants in a few days (Wang et al., 2009). CREATE is a new genome engineering strategy that builds upon MAGE by incorporating CRISPR/Cas9 and barcoding technology. The result is an ability to efficiently generate 100,000's of designer variants in a few days of cloning at the cost of oligos ( $\$ 0.1 /$ variant in materials costs) and map each of these variants onto a selected phenotype using the designed barcode (Garst et al., 2016). 
In this study, CREATE strategies were used for the optimization of the isopropanol production pathway in E. coli (Fig. 1). We first constructed different isopropanol producing variants to investigate the effect of codon optimization, copy number, and translation initiation rates on isopropanol production. After integration of the best isopropanol pathway into the genome, we generated 640 individual RBS library variants by CREATE. After tracking the beneficial mutations, we constructed a combinatorial library containing 256 total variants from four different RBS levels for each gene, and we screened several high yield and productivity integration strains not reported in previous studies.

\section{Materials and methods}

\subsection{Plasmid construction}

For the plasmid harboring the isopropanol synthetic pathway, we chose high-, medium-, and low-copy-number plasmids which were pRS426, pBR322, and pACYC184, respectively. For the isopropanol synthetic pathway, we used a strong constitutive promoter J23119 (http://partsregistry.org/Part:BBa_J23119). All the genes (thl, atoDA, ctfAB, adc, and adh) except atoDA, which was amplified from E.coli MG1655 genome, were synthesized by Integrated DNA Technologies, Inc. with codon optimization for usage in E. coli. The gene cassettes thl, atoDA, adc, and adh or thl, $c t f A B, a d c$, and $a d h$ were co-transformed into Saccharomyces cerevisiae strain BY4709 (ATCC \#200872) with the linearized vector pRS426, which allowed the entire isopropanol synthetic pathway to be assembled into pRS426. The transformed colonies were randomly picked and cultured in SC-Ura media, miniprepped using 
Zymoprep Yeast Plasmid Miniprep II kit (Zymo Research), and PCR amplified for identification of the isopropanol synthetic pathway with the primer pair IPA_ID_F and IPA_ID_R (Table S1). We sequenced the right length plasmid and the right sequencing plasmids, which were designated as pRS426-IPA-1 and pRS426-IPA-2, respectively (Table 1). And then the isopropanol synthetic pathways were amplified from pRS426-IPA-1 and pRS426-IPA-2 by PCR with the primer pair IPA-BamHI and IPA-EagI (Table S1), and ligated into pBR322 and pACYC184 which were also digested by BamHI and EagI to generate pBR322-IPA-1, pBR322IPA-2, pACYC184-IPA-1, and pACYC184-IPA-2 (Table 1).

The pX2-Cas9 plasmid was constructed by amplifying the Cas9 open reading frame from genomic DNA of Streptococcus pyogenes strain SF370 (ATCC \#700294) and cloning into the broad host range plasmid pBTBX-2 (Prior et al., 2010). The pX2-RCas9 plasmid was constructed by two steps. Firstly, the gRNA cassette targeting bla gene was inserted into plasmid pBTBX-2. Then, the Cas9 open reading frame with the original promoter from genomic DNA of Streptococcus pyogenes strain SF370 (ATCC \#700294) was inserted into plasmid pBTBX-2 with the gRNA cassette. The plasmid pSIM5 was acquired from the Court lab (Datta et al., 2006). The gRNA plasmid was purchased from Addgene (\#44251), and different gRNA plasmids were cloned using CPEC (Quan and Tian, 2011). The vector pSS9 containing 600 bp homology arms to SS9 is available in Addgene (\#71655) as well as the corresponding gRNA (SS9_RNA) for integration (Addgene \#71656). Homology arms were amplified from boiled cells of $E$. coli BW23115 (Bassalo et al., 2016). The isopropanol synthetic pathway was amplified from pRS426-IPA-2 by PCR with the primer pair IPA_SS9_F and IPA_SS9_R (Table S1) and the backbone was amplified from pSS9 by PCR with the primer pair SS9_F and SS9_R (Table S1). The plasmid pSS9-IPA was constructed with these two fragments by Gibson assembly method 
and was amplified by PCR with the primers SS9_IPA_F and SS9_IPA_R, which could be used as the linear template for integration into the E. coli genome.

\subsection{Strain construction}

E. coli BW25113 is used as the host strain for the isopropanol synthetic pathway transformation and integration. The constructed plasmids pRS426-IPA-1, pRS426-IPA-2, pBR322-IPA-1, pBR322-IPA-2, pACYC184-IPA-1, and pACYC184-IPA-2 were transformed into E. coli BW25113 to generate the strains PA01, PA02, PA03, PA04, PA05, and PA06. Isopropanol synthetic pathway integration was prepared by transforming gRNA plasmid (SS9_RNA) and the linear template isopropanol synthetic pathway with the homology arms (SS9-J23119-thl-atoDA-adc-adh-SS9) into E. coli BW25113 strain carrying the temperature sensitive pSIM5 plasmid (lambda RED and temperature inducible) and a pX2-cas9 plasmid (arabinose inducible). The plasmid pSIM5 was induced at $42^{\circ} \mathrm{C}$ for $15 \mathrm{~min}$ followed by chilling on ice for 15 min. The cells were washed 3 times with $20 \%$ of the initial culture volume of $\mathrm{ddH}_{2} \mathrm{O}$ (i.e., $10 \mathrm{~mL}$ washes for $50 \mathrm{~mL}$ culture). Following electroporation was at $1800 \mathrm{~V}$ and the cells were recovered in SOB $+0.4 \%$ arabinose to induce Cas9. The cells were recovered 2 hrs before plating on $\mathrm{LB}+0.4 \%$ arabinose $+30 \mu \mathrm{g} / \mathrm{mL}$ kanamycin $+100 \mu \mathrm{g} / \mathrm{mL}$ carbenicillin plates. Then, the plates were cultured at $37^{\circ} \mathrm{C}$ overnight. Next we performed the colony PCR screening by primers SS9_IPA_F and SS9_IPA_R to choose the right integration strain, which was designated as PA07 (Figure S1).

The yeast strain used in this study is Saccharomyces cerevisiae strain BY4709 (ATCC \#200872). Transformed yeast strains were grown in SC-Ura media at $30^{\circ} \mathrm{C}$ for $2-4$ days. Yeast 
transformation-associated recombination cloning (TAR) was conducted as previously described (Shao et al., 2009) but using LiAc transformation (Gietz and Woods, 2006) instead of electroporation.

2.3. Using the RBS Library Calculator to design the RBS libraries for the four isopropanol synthetic pathway enzymes

We designed the initial ribosome binding site sequences for all four enzyme coding sequences to have translation initiation rates of approximately 10,000 au on the RBS Calculator v1.1 proportional scale, which is a quite strong translation rate (Salis et al., 2009). After isopropanol-pathway integration into E. coli BW25113 genome, for each of the four enzyme coding sequences, we used the RBS Library Calculator in Genome Editing (Farasat et al., 2014) to design degenerate genomic RBS libraries to these four enzymes so that a small number of nucleotide mutations could greatly vary the coding sequences' translation rates.

\subsection{RBS library preparation, cloning, and recombineering}

The oligo pools were amplified using library specific oligonucleotides and $1 \mu \mathrm{L}$ of a 1:100 diluted sample of the stock oligo solution. The PCR reactions were as follows: $98^{\circ} \mathrm{C}$ for $60 \mathrm{~s}$ followed by 10 cycles of $98^{\circ} \mathrm{C}_{30 s} / 60^{\circ} \mathrm{C}_{30 s} / 72^{\circ} \mathrm{C}_{90 \mathrm{~s}}$ and then 10 cycles of $98^{\circ} \mathrm{C}_{30 s} / 72^{\circ} \mathrm{C}_{90 \mathrm{~s}}$ followed by a final $5 \min 72^{\circ} \mathrm{C}$ extension hold. Unincorporated oligos and ssDNA were subsequently removed from the amplicon libraries using a Qiaquick PCR cleanup kit. The gRNA plasmid was amplified using the CREATEbb1 and CREATEbb2 primers (Table S1) to prepare a linearized 
backbone for cloning the cassettes. This backbone was treated with DpnI to remove the methylated plasmid template and purified using the Qiaprep kit. Gibson assembly reactions were incubated at $50^{\circ} \mathrm{C}$ for $40 \mathrm{~min}$ using $50-100 \mathrm{ng}$ of backbone and an equimolar amount of CREATE amplicon with NEBuilder ${ }^{\circledR}$ HiFi DNA Assembly Master Mix. Reactions were desalted using dialysis by spotting the reaction on a $0.025 \mu \mathrm{m}$ pore filter floating in $\mathrm{ddH}_{2} \mathrm{O}$. Following desalting, the cloned products were electroporated into E. cloni 10G ELITE Electrocompetent Cells (Lucigen). Libraries were spot plated to $\mathrm{LB}+100 \mu \mathrm{g} / \mathrm{mL}$ carbenicillin to estimate transformation efficiencies and library coverage. Individual and combinatorial RBS libraries were prepared by transforming gRNA plasmid libraries into PA07 carrying pSIM5 and pX2-RCas9 plasmids. The competent cell preparation and electroporation were the same with section 2.2. However, for combinatorial RBS libraries, following electroporation, the cells were recovered in SOB for $2 \mathrm{hrs} .1 / 1000$ of the cells were plated on LB plates with $30 \mu \mathrm{g} / \mathrm{mL}$ kanamycin and $100 \mu \mathrm{g} / \mathrm{mL}$ carbenicillin to test the diversity and genome editing efficiency. Other cells were cultured in LB with $34 \mu \mathrm{g} / \mathrm{mL}$ chloramphenicol, $30 \mu \mathrm{g} / \mathrm{mL}$ kanamycin, and 100 $\mu \mathrm{g} / \mathrm{mL}$ carbenicillin at $30^{\circ} \mathrm{C}$ overnight. After centrifugation, all the cells were transferred to LB with $0.4 \%$ arabinose, $34 \mu \mathrm{g} / \mathrm{mL}$ chloramphenicol, and $30 \mu \mathrm{g} / \mathrm{mL}$ kanamycin for another $24 \mathrm{hrs}$ culture at $30^{\circ} \mathrm{C}$ to remove the gRNA plasmids. Then, $2 \%$ of cells were transferred to LB with 34 $\mu \mathrm{g} / \mathrm{mL}$ chloramphenicol and $30 \mu \mathrm{g} / \mathrm{mL}$ kanamycin for next round recombineering.

Diversity $=\frac{X}{Y} \times 100 \%$

$\mathrm{X}$ means the number of gRNA plasmids with different editing cassettes in the sequencing. Y means the total number of gRNA plasmids in the sequencing.

Genome editing efficiency $=\frac{N}{M} \times 100 \%$ 
$\mathrm{M}$ means the total number of colonies in the sequencing. $\mathrm{N}$ means the number of genome edited colonies in the sequencing.

\subsection{Culture media and fed-batch fermentations}

DNA manipulations and strain construction were grown at $37^{\circ} \mathrm{C}$ or $30^{\circ} \mathrm{C}$ in $\mathrm{LB}$ media (10 $\mathrm{g} / \mathrm{L}$ tryptone, $5 \mathrm{~g} / \mathrm{L}$ yeast extract, $10 \mathrm{~g} / \mathrm{L} \mathrm{NaCl}$ ) as indicated. For isopropanol production, shake flask experiments were carried out in a rotary shaker at $220 \mathrm{rpm}$ and $37^{\circ} \mathrm{C}$ using $250-\mathrm{mL}$ conical flasks each containing $25 \mathrm{~mL}$ of SD-8 medium. SD-8 medium $\left(\mathrm{NH}_{4} \mathrm{Cl}, 7.0\right.$ g/liter; $\mathrm{KH}_{2} \mathrm{PO}_{4}, 7.5$ g/liter; $\mathrm{Na}_{2} \mathrm{HPO}_{4}, 7.5 \mathrm{~g} /$ liter; $\mathrm{K}_{2} \mathrm{SO}_{4}, 0.85 \mathrm{~g} /$ liter; $\mathrm{MgSO}_{4} \cdot 7 \mathrm{H}_{2} \mathrm{O}, 0.17 \mathrm{~g}$ /liter; trace elements, 0.8 $\mathrm{ml} /$ liter; yeast extract; $10 \mathrm{~g} / \mathrm{liter}$ ) [Hanai et al., 2008] containing $2 \%$ glucose was used for fermentations. The trace element solution contained the following (in grams per liter of $5 \mathrm{M}$ $\mathrm{HCl}$ ): $\mathrm{FeSO}_{4} \cdot 7 \mathrm{H}_{2} \mathrm{O}, 40.0 ; \mathrm{MnSO}_{4} \cdot \mathrm{H}_{2} \mathrm{O}, 10.0 ; \mathrm{Al}_{2}\left(\mathrm{SO}_{4}\right)_{3}, 28.3 ; \mathrm{CoCl}_{2} \cdot 6 \mathrm{H}_{2} \mathrm{O}, 4.0 ; \mathrm{ZnSO}_{4} \cdot 7 \mathrm{H}_{2} \mathrm{O}$ 2.0; $\mathrm{Na}_{2} \mathrm{MoO}_{4} \cdot 2 \mathrm{H}_{2} \mathrm{O}, 2.0 ; \mathrm{CuCl}_{2} \cdot 2 \mathrm{H}_{2} \mathrm{O}, 1.0 ;$ and $\mathrm{H}_{3} \mathrm{BO}_{4}, 0.5$. For antibiotic selection, the concentrations of antibiotics were $100 \mu \mathrm{g} / \mathrm{mL}$ (carbenicillin), $34 \mu \mathrm{g} / \mathrm{mL}$ (chloramphenicol), and $30 \mu \mathrm{g} / \mathrm{mL}$ (kanamycin). The $\mathrm{pH}$ was maintained at approximately 6.0 throughout the fermentation by the addition of $5 \mathrm{M} \mathrm{KOH}$ when required.

\subsection{Screening for the RBS libraries}

For the RBS library screening, we cultured the variants in 96-deep well plates with $1 \mathrm{~mL}$ SD- 8 medium containing $2 \%$ glucose at $37^{\circ} \mathrm{C}$ for $48 \mathrm{~h}$. We then measured the cell growth by the spectrophotometer and the concentrations of glucose, isopropanol, acetone, and acetic acid by 
high-performance liquid chromatography (HPLC).

\subsection{Substrate, product, and Proteomic analyses}

Cell growth was monitored by measuring the optical density at $600 \mathrm{~nm}\left(\mathrm{OD}_{600}\right)$. Glucose and the products containing isopropanol, acetone, acetic acid, and ethanol were detected by HPLC (Shimadzu, Kyoto, Japan) with a refractive index detector (RID-10A, Shimadzu, Kyoto, Japan) and a $\mathrm{HPX}-87 \mathrm{H}$ column (Bio-Rad) at $55^{\circ} \mathrm{C}$ with $5 \mathrm{~mm} \mathrm{H}_{2} \mathrm{SO}_{4}$ as the mobile phase at a flow rate of $0.6 \mathrm{ml} / \mathrm{min}$. Proteomic analysis included in-gel digestion (Shevchenko et al., 2006), LC-MS/MS analysis, and data analysis (Supplementary materials and methods S1.1.).

\section{Results and discussion}

\subsection{Rational design and construction of isopropanol synthetic pathway in E. coli}

Gene expression levels depend on codon usage bias, promoter and RBS strength, and plasmid copy numbers (Grote et al., 2005; Gustafsson et al., 2004; Kosuri et al., 2013). To achieve a high isopropanol producing capability, we first synthesized codon optimized versions of all five genes, placed them under the control of the strongest constitutive promoter J23119 in the J231XX promoter family, and inserted strong RBS sequences in front of each gene $(\sim 10,000$ au of translation initiation rates). We then cloned this pathway onto three plasmids with high, medium, and low copy numbers to assess any effect on isopropanol production (Table 3).

All the strains produced isopropanol from an initial glucose concentration of $30 \mathrm{~g} / \mathrm{L}$ under 
aerobic conditions. Since glucose was exhausted within $24 \mathrm{~h}$ after inoculation, we supplemented each culture with $30 \mathrm{~g} / \mathrm{L}$ glucose at $24 \mathrm{hr}$. As shown in Table 3, the strains with lower copy number plasmids achieve higher isopropanol titer and productivity, and the strains that contained atoDA genes produced more isopropanol than those with the $c t f A B$ genes. These results were consistent with expectations based on known enzyme kinetics; the $\mathrm{Km}$ for acetoacetyl-CoA transferase encoded by $\operatorname{ctf} A B(1,200 \mathrm{mM})$ is much higher than that for acetoacetyl-CoA transferase encoded by atoDA $(53.1 \mathrm{mM})$ (Bermejo et al., 1998). In all six strains, PA06 with low-copy-number plasmid pACYC184-IPA-2 produced the greatest amount of isopropanol and the yield of isopropanol reached $0.675(\mathrm{~mol} / \mathrm{mol})$ and the theoretical yield using this pathway was $1 \mathrm{~mol}$ of isopropanol formed from $1 \mathrm{~mol}$ of glucose consumed. Acetone, a metabolic intermediate of isopropanol synthetic pathway (Zhang et al., 2011), accumulated to similar levels relative to isopropanol for each strain, suggesting that the final step may be rate limiting. The byproduct ethanol was not produced at substantial levels $(<0.1 \mathrm{~g} / \mathrm{L}$ in all six strains, data not shown). Similarly, acetate production was minimal compared to wild-type E. coli BW25113, which produced $12 \mathrm{~g} / \mathrm{L}$ acetate after $48 \mathrm{~h}$.

\subsection{Genomic integration and optimization of the isopropanol synthetic pathway}

Stable integration of metabolic pathways into the host genome is important for industrial production (Gaj et al., 2013; Ran et al., 2013). In prior work, we demonstrated that safe-site 9 (ss9) of E. coli BW25113 allows for high expression of heterologous genes (Bassalo et al., 2016). Using the same CRISPR-based integration strategy as reported in Bassalo et al, we integrated the isopropanol synthetic pathway from PA06 into SS9 (Fig. S1). After 72 h, PA06 produced 17.5 
$\mathrm{g} / \mathrm{L}$ of isopropanol with a yield and maximum productivity of $0.62(\mathrm{~mol} / \mathrm{mol})$ and $0.40 \mathrm{~g} / \mathrm{L} / \mathrm{h}$, respectively (Fig. 2A). However, the glucose consumption rate and isopropanol maximum productivity were approximately 2-fold lower in PA07 (integration strain) compared to PA06 (Fig. 2). The concentration of acetone in PA07 cultures was 1.5-fold lower than that in PA06 cultures; however, the concentration of acetate was 3.5-fold higher in PA07 cultures (Fig. 2).

To compare differences in the protein expression levels, proteomic analysis was applied to both strains. The results indicated that the expression level of the $t h l$ gene in PA07 was 5.7-fold higher than that in PA06, but the expression level of atoDA, adc, and adh genes in PA07 were lower than those in PA06 (Fig. S2). The decrease in expression levels of these four genes provides a potential explanation for why PA07 produced lower isopropanol than PA06. To further enhance isopropanol production, we next attempted to balance expression of the various enzymes in the pathway through the construction and screening of an RBS library (Coussement et al., 2014; Kosuri et al., 2013; Ng et al., 2015/5; Zelcbuch et al., 2013).

A designer RBS library was designed using the online tool RBS Library Calculator (https://www.denovodna.com/software/), which has been shown to predict RBS sequences that can affect protein expression levels by several orders of magnitude (Salis et al., 2009; Borujeni et al., 2014). For all five genes, the start codon of atoA overlaps with the stop codon of ato $D$, but there is an upstream RBS within the AG-rich 3' end of atoD that would drive translation of atoA. It seems that the translation of both genes are not significantly coupled. However, the RBS library of atoA gene could potentially mutate the amino acid residues of AtoD. Thus, the RBS library designs for atoA were not considered in this study. The translation rates of RBS libraries designed for isopropanol pathway varied from 4.91 to 43, 6225.98 au (Table S2). The resulting optimized RBS libraries contained a small number of nearby degenerate nucleotides that could 
be readily incorporated into the E. coli genome using the CREATE strategy. CREATE works by using a single plasmid-based cassette that incorporates both an editing module (PAM mutation and Designer Mutation) and a gRNA module. After transformation and induction of Cas9, cells that do not incorporate the plasmid based editing cassette modifications into the homologous site in the genome are killed off. To decrease the cost and increase the coverage of the RBS library, the mutant sites were changed from degenerate primers to $\mathrm{N}$ that means four nucleotides

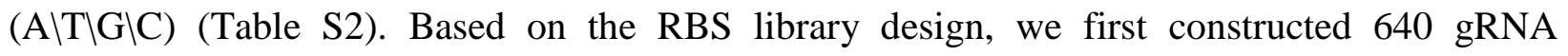
plasmids corresponding to RBS mutations for each of these four enzymes, including $4^{3}$ for acetyl-CoA acetyltransferase, $4^{4}$ for $\alpha$ subunit of acetoacetyl-CoA transferase, $4^{3}$ for acetoacetate decarboxylase, and $4^{4}$ for primary-secondary alcohol dehydrogenase, respectively (Fig. S3, Table S2). After transformation into PA07, the plasmid and genomic DNA sequencing results confirmed that all the construction reached more than $60 \%$ diversity and more than $80 \%$ genome editing efficiency in all the libraries (Fig. S4). We next picked a 3-fold number of colonies for isopropanol production to ensure high coverage of the library, and tested isopropanol production for each individual library.

In the thl RBS library, the titer of isopropanol was not higher than the control strain PA07 (Fig. 3A). We sequenced plasmid and genomic regions of the 20 colonies that generated the highest isopropanol titers. The results showed that $100 \%$ editing efficiency was achieved and that the predicted translation initiation rates ranged from 11,479 to 51,056 au. Although all of their translation initiation rates were higher than that of PA07 (9,975 au), the high expression level for the thl gene did not substantially improve isopropanol production. When translation initiation rates were lower than $2000 \mathrm{au}$, the isopropanol titer of variants were lower than $2 \mathrm{~g} / \mathrm{L}$, and the acetate titer of variants were maximally increased to $7.8 \mathrm{~g} / \mathrm{L}$. We found similar results for the 
atoD RBS library (Fig. 3B). The predicted translation rates of the 20 highest isopropanolproducing variants ranged from 1,025 au to 98,791 au, whereas the translation initiation rate of PA07 was 10,889 au. The fermentation results again suggested that the expression level of atoD did not have a significant effect on pathway flux. For the adc RBS library, we observed a greater diversity of isopropanol production phenotypes compared to the thl and atoD RBS libraries. The results showed that there were 5 variants that produced greater than $4 \mathrm{~g} / \mathrm{L}$ isopropanol produced by PA07 (Fig. 3C). After sequencing the RBS regions, the predicted translation initiation rates of all 5 variants ranged from 31,242-34,339 au, which were all higher than that of PA07 (10,915 au). Furthermore, there were 16 colonies that produced $3 \mathrm{~g} / \mathrm{L}$ to $4 \mathrm{~g} / \mathrm{L}$ isopropanol (Fig. 3C). The sequencing results showed that all the RBS mutants in this category had predicted translation rates of 6,209 to 9,739 au. Moreover, the isopropanol titers of variants were lower than $2 \mathrm{~g} / \mathrm{L}$ when the translation initiation rates were lower than 1000 au. Given the observed relationship between the predicted translation rate for this gene and titer, we constructed an adc RBS mutant with predicted 73,469 au. However, the isopropanol titer was only $2 \mathrm{~g} / \mathrm{L}$ after aerobic culture.

The RBS library of the $a d h$ gene produced the highest isopropanol-producing variants, each generating $\sim 5 \mathrm{~g} / \mathrm{L}$ isopropanol (Fig. 3D). All three RBS mutants had a predicted translation initiation rates of 40,162 au. In addition to these 3 colonies, there were an additional 5 colonies that reached $4 \mathrm{~g} / \mathrm{L}$ (Fig. 3D). The results showed that the translation initiation rates of all the RBS mutants ranged from 10,410 to 15,608 au, and all of them were higher than that of PA07 $(9,095 \mathrm{au})$. Furthermore, there were 6 colonies that produced approximately $3-3.5 \mathrm{~g} / \mathrm{L}$ of isopropanol with the translation initiation rates of 7,262 au. Moreover, the isopropanol titer of variants was lower than $2 \mathrm{~g} / \mathrm{L}$ when the translation initiation rates were lower than $1000 \mathrm{au}$. Similar to the RBS library of the $a d c$ gene, there was a positive correlation between isopropanol 
titer and the predicted translation rates (Fig. S5, S6).

The PA07 integration strain produced more acetate than the plasmid based strains. In the thl and $a t o D$ RBS libraries, there were no strains that produced lower than $3 \mathrm{~g} / \mathrm{L}$ acetate. However, the acetate concentrations were decreased in the $a d c$ and $a d h$ RBS libraries. The variants with 3 $\mathrm{g} / \mathrm{L}$ or lower acetate produced $4 \mathrm{~g} / \mathrm{L}$ or higher isopropanol.

\subsection{Combinatorial RBS modulation on the biosynthesis of isopropanol}

Combinatorial RBS modulation for biochemical production by MAGE has been recently demonstrated ( $\mathrm{Ng}$ et al., 2015). Here, we demonstrate the use of CREATE to generate combinatorial libraries that take advantage of the increased editing afforded by CRISPR/Cas9. It was also recently shown that plasmid curing strategies could be used for combinatorial editing (Jiang et al., 2015; Li et al., 2015; Reisch and Prather, 2015). Thus, to further enhance isopropanol production, we generated a combinatorial RBS library by recursive CREATE.

In the individual RBS libraries of thl and atoD genes, there were no obvious differences when predicted translation rates of RBS reached 1000 au and higher. On the one hand, it is possible these two reactions are not rate-limiting steps. On the other hand, there should be some potential positive mutants when the rate-limiting steps are optimized. Thus, we chose 4 RBS sequences from 1,026 to 51,056 au for thl gene, which were 1,026 au, 5,341 au, 11,479 au, and 51,056 au and another 4 RBS sequences from 1,025 to 98,791 au for atoD genes, which were 1,025 au, 5,066 au, 10,410 au, and 54,548 au. The individual RBS libraries of adc and adh genes had shown significant effects on isopropanol production, and isopropanol titers had a wider diversity than those of the other two genes. To further study the effect of each gene's expression 
on the isopropanol production, we selected 4 RBS levels with a different range of isopropanol titers from each individual RBS library for these two genes. Two of the RBS levels were from the negative mutants, which were selected from the range of isopropanol titers that was lower than $2 \mathrm{~g} / \mathrm{L}$. They had translation initiation rates of 809 au for $a d c$ and 1,002 au for $a d h$. Another RBS was selected from the range of isopropanol titers that was 2 to $4 \mathrm{~g} / \mathrm{L}$ with translation initiation rates of 5,675 au for $a d c$ and 5,066 au for $a d h$. The next two RBS's were selected from the range of isopropanol titers that were $4 \mathrm{~g} / \mathrm{L}$ and higher, with translation initiation rates of 9,739 au and 34,339 au for adc and 10,410 au and 40,162 au for adh. After each round of electroporation, 1/1000 of the transformation was plated to test the CREATE efficiency, and the other transformation was transferred to LB with $0.4 \%$ arabinose to cure the gRNA plasmids for $24 \mathrm{~h}$ culture. As a result, each round of genome editing efficiency was higher than $80 \%$ and all four RBS mutations can be found in each CREATE round during the sequencing (Fig. S7). Meanwhile, each round of gRNA plasmid curing efficiency was higher than 99\% (Fig. S7).

After 4 rounds of recursive CREATE, we achieved a $4^{4}$ total library size for the combinatorial RBS modulation on the biosynthesis of isopropanol. We picked a 3-fold number of colonies for isopropanol production to ensure high coverage of the library. The results showed that $5 \%$ of the mutants produced $>4.5 \mathrm{~g} / \mathrm{L}$ isopropanol, while $2 \%$ of the colonies produced $>5$ g/L isopropanol (Fig. 4A). The translation rates for the RBS mutants of $a d c$ and $a d h$ genes in all the variants that produced $4.5 \mathrm{~g} / \mathrm{L}$ and higher isopropanol were $>10,000$ au (Fig. 4D, Fig. 4E). Furthermore, the RBS level of the best strain in all the variants was the combination of 34,339 au and 40,162 au for the $a d c$ and $a d h$ genes (Fig. 4D, Fig. 4E). This suggests that isopropanol production may be further enhanced by up-regulation of these two genes.

CREATE is a new strategy for rapid design and construction of production strains. For 
isopropanol production, we designed and constructed 640 variants for the individual RBS library by RBS Library Calculator and CREATE in only 2 days. Furthermore, the high genome editing efficiency meant that we only needed to test at 3 -fold coverage to ensure we sampled the intended diversity (at lower editing efficiency the majority of the sampled strains would be wildtype). The titer of isopropanol of the best variant in combinatorial RBS library was 1.2 -fold higher than that of the best from the individual RBS library and 1.5-fold of the initial integration strain. However, the increases in the translation initiation rates of a few genes by modifying RBS sequences in the genome did not overcome the difference between the strains expressing genes in the plasmid and in the genome. We think further optimization on the promoter in the integration strain is an option, although we note that J23119 is already very strong. It is also possible to put additional copies of the gene into the genome. The overall product titers were only modestly improved by applying CREATE, suggesting that other barriers are impeding higher production of isopropanol. Firstly, a lot of acetic acid was accumulated after much glucose was consumed, so we need to knock out or down-regulate the genes of the competing pathways. Secondly, low pH and the accumulation of isopropanol drastically reduced production yields, so we need to optimize the fermentation regulation strategies such as $\mathrm{pH}$ control, glucose addition, and product removal with gas stripping.

\subsection{Proteomic analysis of the RBS library variants for isopropanol production}

The aim of the RBS libraries for all four enzymes is to change the protein expression level

of the isopropanol synthetic pathway. While the RBS library calculator provided predictions of protein expression of each of the targeted enzymes (Table S2), the actual protein expression data 
had not yet been measured. Moreover, the prediction data from RBS Library Calculator does not account for upstream translation (now available through the Operon Calculator (https://www.denovodna.com/software/), Ng et al., 2015). Thus, to further study the effect of RBS libraries on protein expression of the isopropanol pathway, several variants were selected from the individual and combinatorial RBS libraries for proteomic analysis (Fig. 5). All the samples were collected for proteomics testing after $24 \mathrm{~h}$ flask fermentation, and isopropanol production of all the variants were shown in Table 4. The RBS designs and evaluations of all the selected variants can be found in Table 4 .

To analyze the proteomics data, the spectral count of the protein in PA14 was normalized to 1.0 as a standard value (Fig. 5). For the acetyl-CoA acetyltransferase, the $\mathrm{p}$ value is $<0.05$, which means the expression level had a positive correlation with the RBS design (Fig. 5A). However, there was no obvious difference on the isopropanol titer in the RBS library of thl when the design of the translation initiation rate is higher than 14,378 au. Similar results were obtained in the $\alpha$ subunit of acetoacetyl-CoA transferase. The expression level of $\alpha$ subunit of acetoacetylCoA transferase was positively correlated with the RBS design $(\mathrm{p}<0.05)$, and there was also no obvious difference on the isopropanol titer in the RBS library of atoD when the design of the translation initiation rate is higher than 228 au (Fig. 5B). Based on the data from the RBS library fermentation, proteomic data provided further evidence that the reactions catalyzed by acetylCoA acetyltransferase and acetoacetyl-CoA transferase should not be rate-limiting steps. For the acetoacetate decarboxylase, the expression level was positively correlated with the RBS design ( $\mathrm{p}$ value < 0.05) (Fig. 5C). Conversely, the higher the expression level of adc, the higher isopropanol productivity was achieved when the variants had the same RBS level of adh (Table 4). Similar results were found in the proteomic data for $a d h$ (p value $<0.05$ ) (Fig. 5D). The 
higher RBS levels enhanced the isopropanol productivity when the variants had the same RBS design for $a d c$ (Table 4). In other words, the isopropanol productivity was decreased when $a d c$ or $a d h$ genes were down-regulated. After $24 \mathrm{~h}$ culture, the isopropanol productivity of PA11 and PA12 were $33 \%$ and $10 \%$ lower than that of the control strain PA07, respectively. Furthermore, the lowest productivity was found in PA13 which has the lowest expression level of $a d c$ and $a d h$ genes. Moreover, the proteomic data confirmed that the combination of the highest translation initiation rates for $a d c$ and $a d h$ genes reached the highest protein expression. During the $24 \mathrm{~h}$ flask fermentation, the yield of the best variant PA14 reached $0.75(\mathrm{~mol} / \mathrm{mol})$, and the maximum productivity of isopropanol was $0.62 \mathrm{~g} / \mathrm{L} / \mathrm{h}(12-24 \mathrm{~h})$, which is 2.8 -fold of the control strain PA07, and the acetate titer in PA14 was 0.67-fold of that in PA07 (Table 4).

\section{Conclusions}

In this study, we first investigated the effect of codon optimization, copy number, and translation initiation rates on isopropanol production. After codon optimization, the strain PA06 containing $\sim 10,000$ au of translation initiation rates for all genes in the isopropanol synthetic pathway produced isopropanol at titers of $17.5 \mathrm{~g} / \mathrm{L}$, a yield of $0.62(\mathrm{~mol} / \mathrm{mol})$, and a maximum productivity of $0.40 \mathrm{~g} / \mathrm{L} / \mathrm{h}$ with low-copy-number plasmid. After integration of isopropanol synthetic pathway into the genome, the CREATE strategy was applied to construct and test 903 individual and combinatorial variants of the isopropanol production pathway in E. coli. The best producing variant contained combinatorial RBS mutants (the $t h l$ gene with a translation initiation rate of $51,056 \mathrm{au}$, the $a t o D$ gene with a translation initiation rate of $10,410 \mathrm{au}$, the $a d c$ gene with a translation initiation rate of $31,242 \mathrm{au}$, and the $a d h$ gene with a translation initiation rate of 
$40,162 \mathrm{au})$ and produced isopropanol at titers of $7.1 \mathrm{~g} / \mathrm{L}$, a yield of $0.75(\mathrm{~mol} / \mathrm{mol})$, and a maximum productivity of $0.62 \mathrm{~g} / \mathrm{L} / \mathrm{h}$. These results showed that the CREATE strategy can be used for the construction and testing of close to $\sim 1000$ rationally designed strains in a few days and can improve production through combinatorial modifications.

\section{Acknowledgements}

We thank the support by the department of Energy grant (DE-FOA-0000996).

\section{References}

Bassalo, M.C., Garst, A.D., Halweg-Edwards, A.L., Grau, W.C., Domaille, D.W., Mutalik, V.K., Arkin, A.P., Gill, R.T., 2016. Rapid and efficient one-step metabolic pathway integration in E. coli. ACS Synth. Biol. 5, 561-568.

Bermejo, L.L., Welker, N.E., Papoutsakis, E.T., 1998. Expression of Clostridium acetobutylicum ATCC 824 Genes in Escherichia coli for acetone production and acetate detoxification. Appl. Environ. Microbiol. 64, 1079-1085.

Borujeni, A.E., Channarasappa, A.S., Salis, H.M., 2014. Translation rate is controlled by coupled trade-offs between site accessibility, selective RNA unfolding and sliding at upstream standby sites. Nucleic Acids Res. 42(4), 2646-2659.

Coussement, P., Maertens, J., Beauprez, J., Van Bellegem, W., De Mey, M., 2014. One step DNA assembly for combinatorial metabolic engineering. Metab. Eng. 23, 70-77.

Datta, S., Costantino, N., Court, D.L., 2006. A set of recombineering plasmids for gram-negative 
bacteria. Gene 379, 109-115.

Endy, D., 2005. Foundations for engineering biology. Nature 438, 449-453.

Farasat, I., Kushwaha, M., Collens, J., Easterbrook, M., Guido, M., Salis, H.M., 2014. Efficient search, mapping, and optimization of multi-protein genetic systems in diverse bacteria. Mol. Syst. Biol. 10, 731.

Gaj, T., Gersbach, C.A., Barbas, C.F., 2013. ZFN, TALEN, and CRISPR/Cas-based methods for genome engineering. Trends Biotechnol. 31, 397-405.

Garst, A., Bassalo, M.C., Pine, G., Lynch, S.A., Halweg-Edwards, A.L, Liu R.M., Liang, L.Y., Wang, Z.W., Zeitoun, R., Alexander, W.G., Gill, R.T.,2017. Genome-Scale sequence to activity relationship mapping at single nucleotide resolution Nature Bio. 35, 48-55.

Gietz, R.D., Woods, R.A., 2006. Yeast transformation by the LiAc/SS Carrier DNA/PEG method. Methods Mol. Biol. 313, 107-120.

Grote, A., Hiller, K., Scheer, M., Münch, R., Nörtemann, B., Hempel, D.C., Jahn, D., 2005. JCat: a novel tool to adapt codon usage of a target gene to its potential expression host. Nucleic Acids Res. 33, W526-W531.

Gustafsson, C., Govindarajan, S., Minshull, J., 2004. Codon bias and heterologous protein expression. Trends Biotechnol. 22, 346-353.

Hanai, T., Atsumi, S., Liao, J.C., 2007. Engineered synthetic pathway for isopropanol production in Escherichia coli. Appl. Environ. Microbiol. 73, 7814-7818.

Inokuma, K., Liao, J.C., Okamoto, M., Hanai, T., 2010. Improvement of isopropanol production by metabolically engineered Escherichia coli using gas stripping. J. Biosci. Bioeng. 110, 696-701. 
Jiang, Y., Chen, B., Duan, C., Sun, B., Yang, J., Yang, S., 2015. Multigene editing in the Escherichia coli genome via the CRISPR-Cas9 system. Appl. Environ. Microbiol. 81, 25062514.

Jojima, T., Inui, M., Yukawa, H., 2008. Production of isopropanol by metabolically engineered Escherichia coli. Appl. Microbiol. Biotechnol. 77, 1219-1224.

Kosuri, S., Goodman, D.B., Cambray, G., Mutalik, V.K., Gao, Y., Arkin, A.P., Endy, D., Church, G.M., 2013. Composability of regulatory sequences controlling transcription and translation in Escherichia coli. Proc. Natl. Acad. Sci. USA 110, 14024-14029.

Lee, I., Johnson, L.A., Hammond, E.G., 1995. Use of branched-chain esters to reduce the crystallization temperature of biodiesel. J. Am. Oil Chem. Soc. 72, 1155-1160.

Li, Y., Lin, Z., Huang, C., Zhang, Y., Wang, Z., Tang, Y.-J., Chen, T., Zhao, X., 2015. Metabolic engineering of Escherichia coli using CRISPR-Cas9 meditated genome editing. Metab. Eng. 31, 13-21.

Ng, C.Y., Farasat, I., Maranas, C.D., Salis, H.M., 2015. Rational design of a synthetic EntnerDoudoroff pathway for improved and controllable NADPH regeneration. Metab. Eng. 29, 86-96.

Osburn, O.L., Brown, R.W., Werkman, C.H., 1937. The butyl alcohol-isopropyl alcohol fermentation. J. Biol. Chem. 121, 685-695.

Prior, J.E., Lynch, M.D., Gill, R.T., 2010. Broad-host-range vectors for protein expression across gram negative hosts. Biotechnol. Bioeng. 106(2), 326-332.

Quan, J., Tian, J., 2011. Circular polymerase extension cloning for high-throughput cloning of complex and combinatorial DNA libraries. Nat. Protoc. 6, 242-251. 
Ragauskas, A.J., Williams, C.K., Davison, B.H., Britovsek, G., Cairney, J., Eckert, C.A., Frederick, W.J., Jr, Hallett, J.P., Leak, D.J., Liotta, C.L., Mielenz, J.R., Murphy, R., Templer, R., Tschaplinski, T., 2006. The path forward for biofuels and biomaterials. Science $311,484-489$.

Ran, F.A., Hsu, P.D., Lin, C.-Y., Gootenberg, J.S., Konermann, S., Trevino, A.E., Scott, D.A., Inoue, A., Matoba, S., Zhang, Y., Zhang, F., 2013. Double nicking by RNA-guided CRISPR Cas9 for enhanced genome editing specificity. Cell 155, 479-480.

Reisch, C.R., Prather, K.L.J., 2015. The no-SCAR (Scarless Cas9 Assisted Recombineering) system for genome editing in Escherichia coli. Sci. Rep. 5, 15096.

Salis, H.M., Mirsky, E.A., Voigt, C.A., 2009. Automated design of synthetic ribosome binding sites to control protein expression. Nat. Biotechnol. 27, 946-950.

Shao, Z., Zhao, H., Zhao, H., 2009. DNA assembler, an in vivo genetic method for rapid construction of biochemical pathways. Nucleic Acids Res. 37, e16.

Shevchenko, A., Tomas, H., Havlis, J., Olsen, J.V., Mann, M., 2006. In-gel digestion for mass spectrometric characterization of proteins and proteomes. Nat. Protoc. 1, 2856-2860.

Stephanopoulos, G., 2012. Synthetic biology and metabolic engineering. ACS Synth. Biol. 1, $514-525$.

Stephanopoulos, G., 2007. Challenges in engineering microbes for biofuels production. Science $315,801-804$.

Survase, S.A., Jurgens, G., van Heiningen, A., Granström, T., 2011. Continuous production of isopropanol and butanol using Clostridium beijerinckii DSM 6423. Appl. Microbiol. Biotechnol. 91, 1305-1313.

Tamakawa, H., Mita, T., Yokoyama, A., Ikushima, S., Yoshida, S., 2013. Metabolic engineering 23 
of Candida utilis for isopropanol production. Appl. Microbiol. Biotechnol. 97, 6231-6239.

Tuck, C.O., Pérez, E., Horváth, I.T., Sheldon, R.A., Poliakoff, M., 2012. Valorization of biomass: deriving more value from waste. Science 337, 695-699.

Wang, H.H., Isaacs, F.J., Carr, P.A., Sun, Z.Z., Xu, G., Forest, C.R., Church, G.M., 2009. Programming cells by multiplex genome engineering and accelerated evolution. Nature 460, 894-898.

Warner, J.R., Reeder, P.J., Karimpour-Fard, A., Woodruff, L.B.A., Gill, R.T., 2010. Rapid profiling of a microbial genome using mixtures of barcoded oligonucleotides. Nat. Biotechnol. 28, 856-862.

Yadav, V.G., De Mey, M., Lim, C.G., Ajikumar, P.K., Stephanopoulos, G., 2012. The future of metabolic engineering and synthetic biology: towards a systematic practice. Metab. Eng. 14, 233-241.

Zelcbuch, L., Antonovsky, N., Bar-Even, A., Levin-Karp, A., Barenholz, U., Dayagi, M., Liebermeister, W., Flamholz, A., Noor, E., Amram, S., Brandis, A., Bareia, T., Yofe, I., Jubran, H., Milo, R., 2013. Spanning high-dimensional expression space using ribosomebinding site combinatorics. Nucleic Acids Res. 41, e98.

Zhang, F., Rodriguez, S., Keasling, J.D., 2011. Metabolic engineering of microbial pathways for advanced biofuels production. Curr. Opin. Biotechnol. 22, 775-783. 


\section{Table 1}

Plasmids used in this study.

\begin{tabular}{|c|c|c|}
\hline Name & Description & Source \\
\hline pRS426 & $\begin{array}{l}\text { Multiple copy plasmid with URA3 } \\
\text { marker }\end{array}$ & ATCC \\
\hline pBR322 & $\begin{array}{l}\text { Medium copy cloning vector containing } \\
\text { the origin of replication from pMB1 } \\
\text { p15A origin of replication }\end{array}$ & $\begin{array}{l}\text { New } \\
\text { Biolabs }\end{array}$ \\
\hline pACYC184 & $\begin{array}{l}\text { Low copy cloning vector containing the } \\
\text { p15A origin of replication }\end{array}$ & $\begin{array}{l}\text { New } \\
\text { Biolabs }\end{array}$ \\
\hline pSIM5 & $\begin{array}{l}\text { The temperature sensitive plasmid } \\
\text { containing pSC101 origin }\end{array}$ & Datta et al., 2006 \\
\hline pX2-Cas9 & Inducibly expressing Cas9 & This study \\
\hline pX2-RCas9 & $\begin{array}{l}\text { Inducibly gRNA cassette targeting bla } \\
\text { gene and contitutive expressing Cas } 9\end{array}$ & This study \\
\hline gRNA & $\begin{array}{l}\text { Directing Cas9 to introduce a precise } \\
\text { double strand break (DSB) in the } \\
\text { genome }\end{array}$ & Addgene \\
\hline
\end{tabular}




\begin{tabular}{|c|c|c|}
\hline \multirow[t]{2}{*}{ pSS9 } & \multicolumn{2}{|c|}{ Containing $600 \mathrm{bp}$ homology arms to Addgene } \\
\hline & $\begin{array}{l}\text { SS9 for one-step markerless genome } \\
\text { integration in E. coli }\end{array}$ & \\
\hline SS9_RNA & SS9-targeting gRNA for & Addgene \\
\hline & transformation with pSS9-IPA & \\
\hline pSS9-IPA & Containing $600 \mathrm{bp}$ homology arms to & This study \\
\hline & SS9 and isopropanol synthetic pathway & \\
\hline pRS426-IPA-1 & pRS426-J23119-thl-ctfAB-adc-adh & This study \\
\hline pRS426-IPA-2 & pRS426-J23119-thl-atoDA-adc-adh & This study \\
\hline pBR322-IPA-1 & pBR322-J23119-thl-ctfAB-adc-adh & This study \\
\hline pBR322-IPA-2 & pBR322-J23119-thl-atoDA-adc-adh & This study \\
\hline pACYC184-IPA-1 & pACYC184-J23119- thl-ctfAB-adc-adh & This study \\
\hline pACYC184-IPA-2 & pACYC184-J23119-thl-atoDA-adc-adh & This study \\
\hline
\end{tabular}




\section{Table 2}

Strains used in this study.

\begin{tabular}{|c|c|c|}
\hline Name & Description & Source \\
\hline Saccharomyces & MATalpha ura3deltaO & ATCC \\
\hline \multicolumn{3}{|l|}{ cerevisiae BY4709 } \\
\hline \multirow[t]{3}{*}{ E. coli BW25113 } & $\operatorname{lacl}^{\mathrm{q}} r r n B_{\mathrm{T} 14} \Delta l a c Z_{\mathrm{WJ} 16} h s d R 514 \Delta a r a B A D_{\mathrm{AH} 33}$ & CGSC \\
\hline & $\triangle r h a B A D_{\mathrm{LD} 78}$, derivatives of the $\mathrm{F}^{-}, \lambda^{-}, E$. coli & \\
\hline & K-12 strain BD792 & \\
\hline E.coli MG1655 & $\mathrm{F}^{-}$, lambda ${ }^{-}, \mathrm{rph}-1$ & ATCC \\
\hline PA01 & BW25113/pRS426-IPA-1 & This study \\
\hline PA02 & BW25113/pRS426-IPA-2 & This study \\
\hline PA03 & BW25113/pBR322-IPA-1 & This study \\
\hline PA04 & BW25113/pBR322-IPA-2 & This study \\
\hline PA05 & BW25113/pACYC184-IPA-1 & This study \\
\hline PA06 & BW25113/pACYC184-IPA-2 & This study \\
\hline PA07 & BW25113, J23119-thl-atoDA-adc-adh $h_{\text {intergration }}$ & This study \\
\hline PA07' & PA07, pX2-Rcas9, pSIM5 & This study \\
\hline
\end{tabular}




\section{Table 3}

Isopropanol production in $E$. coli after $48 \mathrm{~h}$ in $250 \mathrm{ml}$ flasks containing $25 \mathrm{ml} \mathrm{SD}-8$ medium with addition of $\mathrm{KOH}$ to $\mathrm{pH}$ about 6.0.

\begin{tabular}{|c|c|c|c|c|c|}
\hline Strains & OD600 at $48 \mathrm{~h}^{\mathrm{b}}$ & $\begin{array}{l}\text { Glucose } \\
\text { consumed }^{b} \\
(\mathrm{~g} / \mathrm{L})\end{array}$ & $\begin{array}{l}\text { Isopropanol } \\
(\mathrm{g} / \mathrm{L})^{\mathrm{b}}\end{array}$ & $\begin{array}{l}\text { Acetone } \\
(\mathrm{g} / \mathrm{L})^{\mathrm{b}}\end{array}$ & $\begin{array}{l}\text { Acetic acid } \\
(\mathrm{g} / \mathrm{L})^{\mathrm{b}}\end{array}$ \\
\hline BW25113 & $10.0 \pm 0.2$ & $35.2 \pm 0.2$ & $\mathrm{ND}^{\mathrm{a}}$ & $\mathrm{ND}^{\mathrm{a}}$ & $12.0 \pm 0.2$ \\
\hline PA01 & $12.1 \pm 0.4$ & $40.0 \pm 0.2$ & $5.6 \pm 0.1$ & $1.0 \pm 0.1$ & $3.4 \pm 0.1$ \\
\hline PA02 & $13.2 \pm 0.1$ & $45.6 \pm 0.3$ & $7.5 \pm 0.2$ & $1.3 \pm 0.2$ & $2.8 \pm 0.2$ \\
\hline PA03 & $12.8 \pm 0.3$ & $48.2 \pm 0.1$ & $8.6 \pm 0.1$ & $1.6 \pm 0.2$ & $2.0 \pm 0.2$ \\
\hline PA04 & $13.6 \pm 0.2$ & $56.4 \pm 0.3$ & $10.8 \pm 0.3$ & $1.9 \pm 0.3$ & $1.5 \pm 0.1$ \\
\hline PA05 & $13.4 \pm 0.1$ & $55.5 \pm 0.2$ & $11.6 \pm 0.2$ & $2.2 \pm 0.1$ & $1.6 \pm 0.3$ \\
\hline PA06 & $14.2 \pm 0.4$ & $60.0 \pm 0.2$ & $13.5 \pm 0.1$ & $2.5 \pm 0.2$ & $1.4 \pm 0.1$ \\
\hline
\end{tabular}

${ }^{\mathrm{a}}$ ND: not detected.

${ }^{\mathrm{b}}$ Each value is the mean of three parallel replicates \pm standard deviation. 


\section{Table 4}

The RBS designs and evaluations of all the selected variants and isopropanol and acetate production after $24 \mathrm{~h}$ flask fermentation.

\begin{tabular}{|c|c|c|c|c|c|c|}
\hline \multirow[t]{2}{*}{ Strains } & $\begin{array}{l}\text { thl } \\
\text { translation }\end{array}$ & $\begin{array}{l}\text { atoDA } \\
\text { translation }\end{array}$ & $\begin{array}{l}a d c \\
\text { translation }\end{array}$ & $\begin{array}{l}\text { adh } \\
\text { translation }\end{array}$ & $\begin{array}{l}\text { Isopropanol } \\
(\mathrm{g} / \mathrm{L})^{\mathrm{a}}\end{array}$ & $\begin{array}{l}\text { Acetate } \\
(\mathrm{g} / \mathrm{L})^{\mathrm{a}}\end{array}$ \\
\hline & rate $(\mathrm{au})$ & rate $(\mathrm{au})$ & rate $(\mathrm{au})$ & rate $(\mathrm{au})$ & & \\
\hline \multirow[t]{2}{*}{ PA07 } & 13532 & 2421 & 10915 & 3060 & $3.9 \pm 0.2$ & $2.1 \pm 0.1$ \\
\hline & (9975) & (10889) & (10915) & (9095) & & \\
\hline \multirow[t]{2}{*}{ PA11 } & 57051 & 8296 & 1286 & 7597 & $2.6 \pm 0.1$ & $2.4 \pm 0.2$ \\
\hline & (51056) & (10410) & (809) & (10410) & & \\
\hline \multirow[t]{2}{*}{ PA12 } & 14378 & 8296 & 1286 & 29308 & $3.5 \pm 0.3$ & $2.2 \pm 0.1$ \\
\hline & (11479) & (10410) & (809) & (40162) & & \\
\hline \multirow[t]{2}{*}{ PA13 } & 57051 & 228 & 1286 & 584 & $0.5 \pm 0.1$ & $3.0 \pm 0.2$ \\
\hline & (51056) & (1025) & (809) & (1002) & & \\
\hline \multirow[t]{2}{*}{ PA14 } & 57051 & 8296 & 33626 & 29308 & $7.1 \pm 0.2$ & $1.4 \pm 0.1$ \\
\hline & (51056) & (10410) & (31242) & (40162) & & \\
\hline \multirow[t]{2}{*}{ PA15 } & 1138 & 16812 & 2704 & 29308 & $5.5 \pm 0.2$ & $1.7 \pm 0.1$ \\
\hline & (1026) & (54548) & (9739) & (40162) & & \\
\hline
\end{tabular}

${ }^{\text {a }}$ Each value is the mean of three parallel replicates \pm standard deviation. 
b The data inside and outside brackets were designs from RBS Library Calculator and evaluations from Operon Calculator, respectively.

\section{Figure legends}

Fig.1 The synthetic pathway of isopropanol in E. coli BW25113. The dashed line indicates omitted steps.

Fig. 2 Isopropanol production by engineered E. coli in glucose fed-batch fermentation for $72 \mathrm{~h}$ by the addition of $5 \mathrm{M} \mathrm{KOH}$ to keep $\mathrm{pH}$ at 6.0. (A) PA06 was the plasmid strain (BW25113pACYC184-J23119-thl-atoDA-adc-adh; (B) PA07 was the isopropanol synthetic pathway integration strain (BW25113-J23119-thl-atoDA-adc-adh). Each value is the mean of three parallel replicates \pm standard deviation.

Fig.3 Isopropanol and acetate production with a 3-fold number of colonies for each individual RBS library with 96-deep well plate culture and $1 \mathrm{~mL}$ SD-8 medium containing $2 \%$ glucose at $37^{\circ} \mathrm{C}$ for $48 \mathrm{~h}$. Note: colorful sites are high isopropanol-producing variants mentioned in the text, and shown with translation initiation rates in the inner plot. Each color represents the same translation initiation rates. The parent strain PA07 and low isopropanol-producing variants mentioned in the text were shown with translation initiation rates in the outer plot, and these data-points were shown in bigger size. (A) thl RBS library with 192 colony culture; (B) atoDA RBS library with 768 colony culture; (C) $a d c$ RBS library with 192 colony culture; (D) adh RBS library with 768 colony culture.

Fig.4 Isopropanol and acetate production with 3-fold number of combinatorial RBS libraries with 96-deep well plate culture and $1 \mathrm{~mL} \mathrm{SD}-8$ medium containing $2 \%$ glucose at $37^{\circ} \mathrm{C}$ for $48 \mathrm{~h}$. 
(A) Isopropanol and acetate production were conducted with the whole combinatorial RBS libraries. High isopropanol-producing variants mentioned in the text were shown with red color, and the parent strain PA07 was shown in bigger size with blue color. (B) The translation initiation rates of $t h l$ gene was shown from the positive variants which generated higher than 4.5 $\mathrm{g} / \mathrm{L}$ isopropanol; (C) The translation initiation rates of atoDA gene was shown from the positive variants which generated higher than $4.5 \mathrm{~g} / \mathrm{L}$ isopropanol; (D) The translation initiation rates of $a d c$ gene was shown from the positive variants which generated higher than $4.5 \mathrm{~g} / \mathrm{L}$ isopropanol; (E) The translation initiation rates of $a d h$ gene was shown from the positive variants which generated higher than $4.5 \mathrm{~g} / \mathrm{L}$ isopropanol. Each color represents the same translation initiation rates.

Fig.5 Proteomic analysis of the RBS library variants with LC-MS/MS method. Note: All the data points were average from three replications. The data inside and outside brackets were designs from RBS Library Calculator and evaluations from Operon Calculator, respectively. The p value was calculated with translation initiation rates of RBS designs as experimental results and LCMS/MS counts of RBS mutations as expected results. When $\mathrm{p}$ value is lower than the significance value (0.05), it means the translation initiation rates of RBS designs were positive correlation with protein expression level. (A) acetyl-CoA acetyltransferase ( $\mathrm{p}$ value $=0.001213$ ); (B) acetoacetyl-CoA transferase ( $\mathrm{p}$ value $=0.037491)$; (C) acetoacetate decarboxylase $(\mathrm{p}$ value $=$ 0.014902); (D) primary-secondary alcohol dehydrogenase ( $\mathrm{p}$ value $=0.007666$ ) 
Glucose

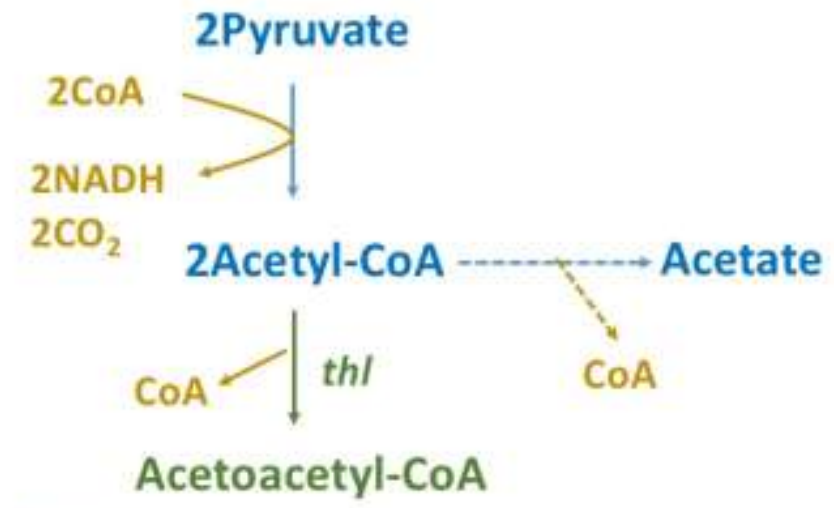

Fig.1 


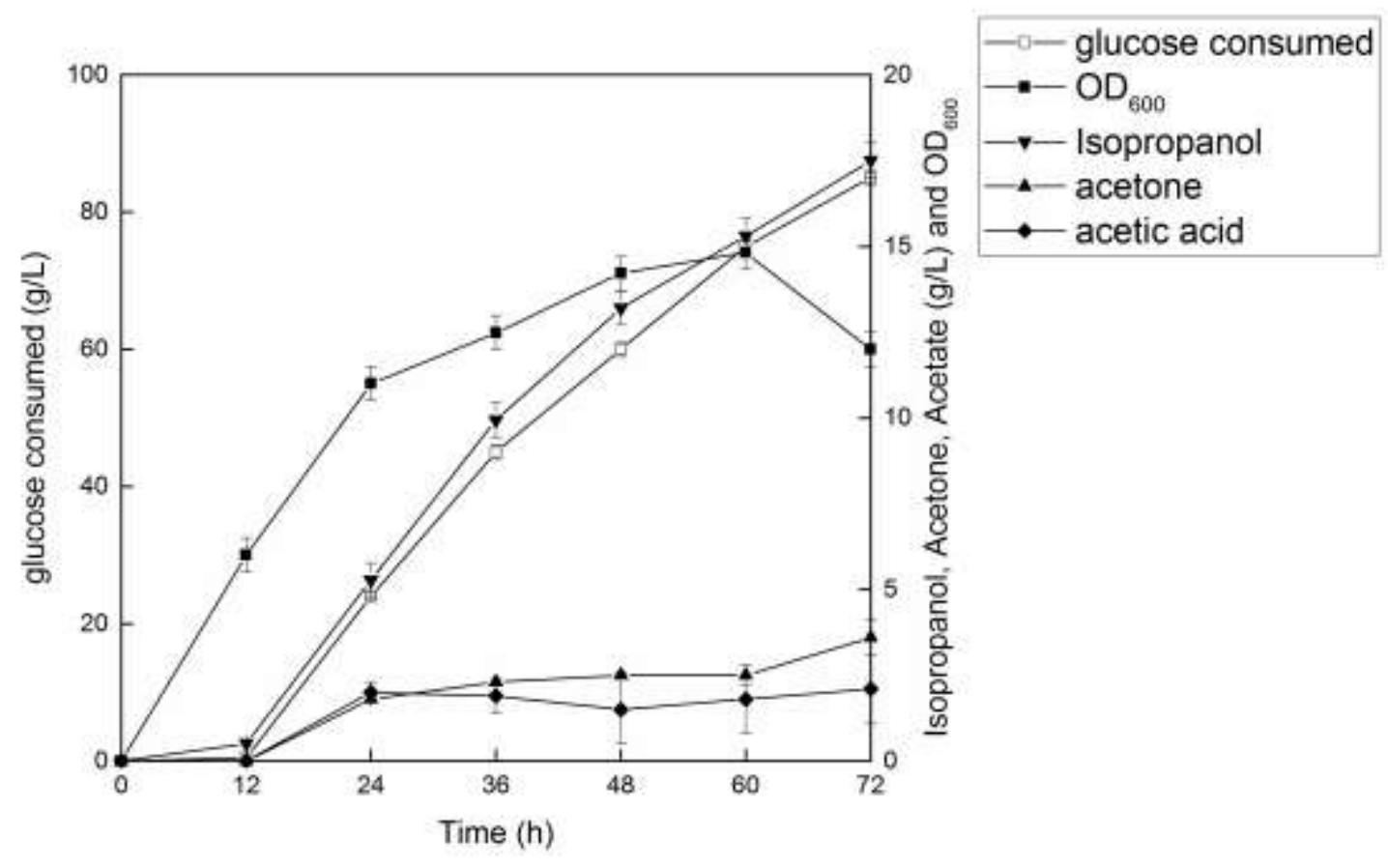

Fig.2A

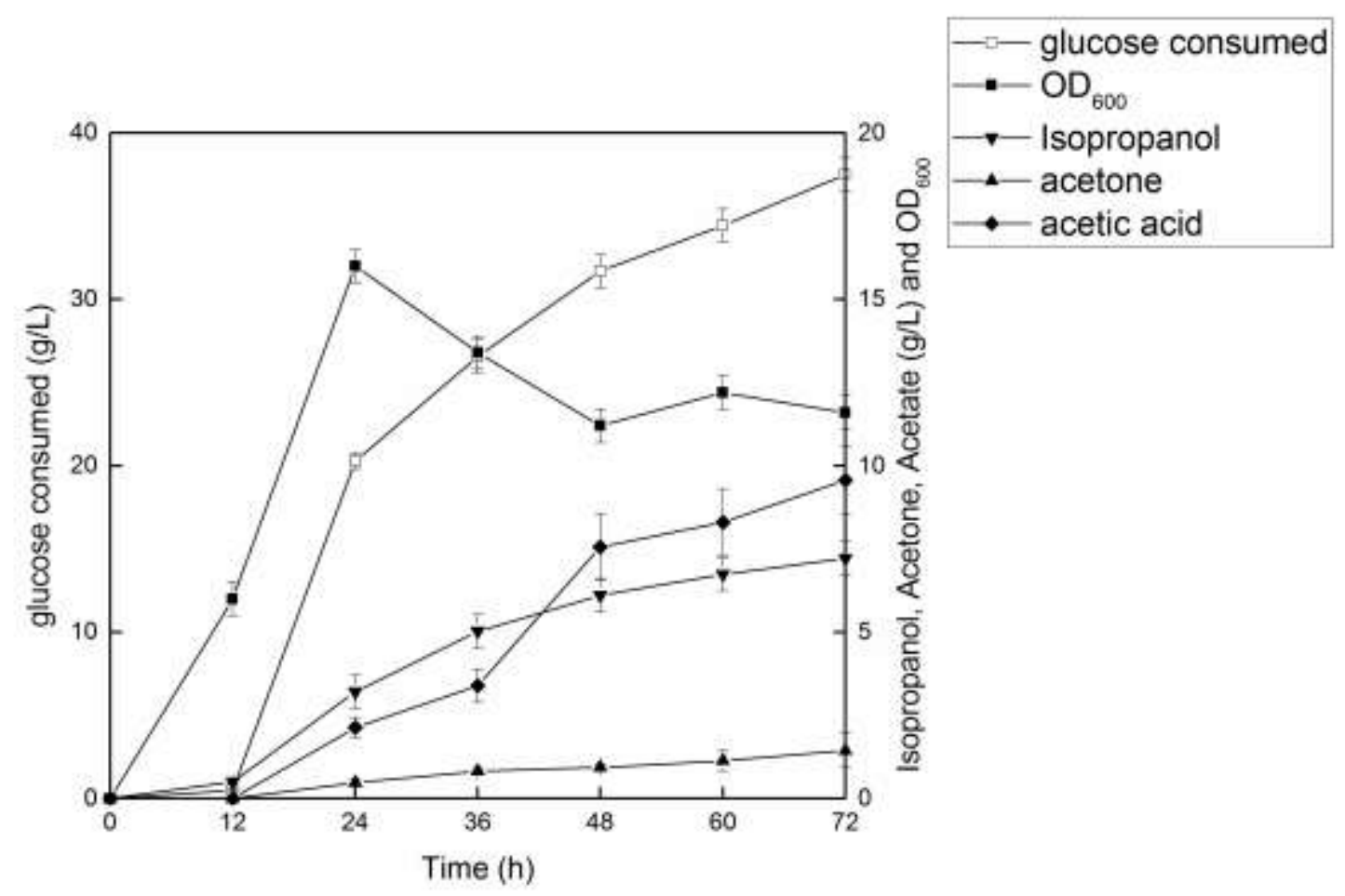

Fig.2B 


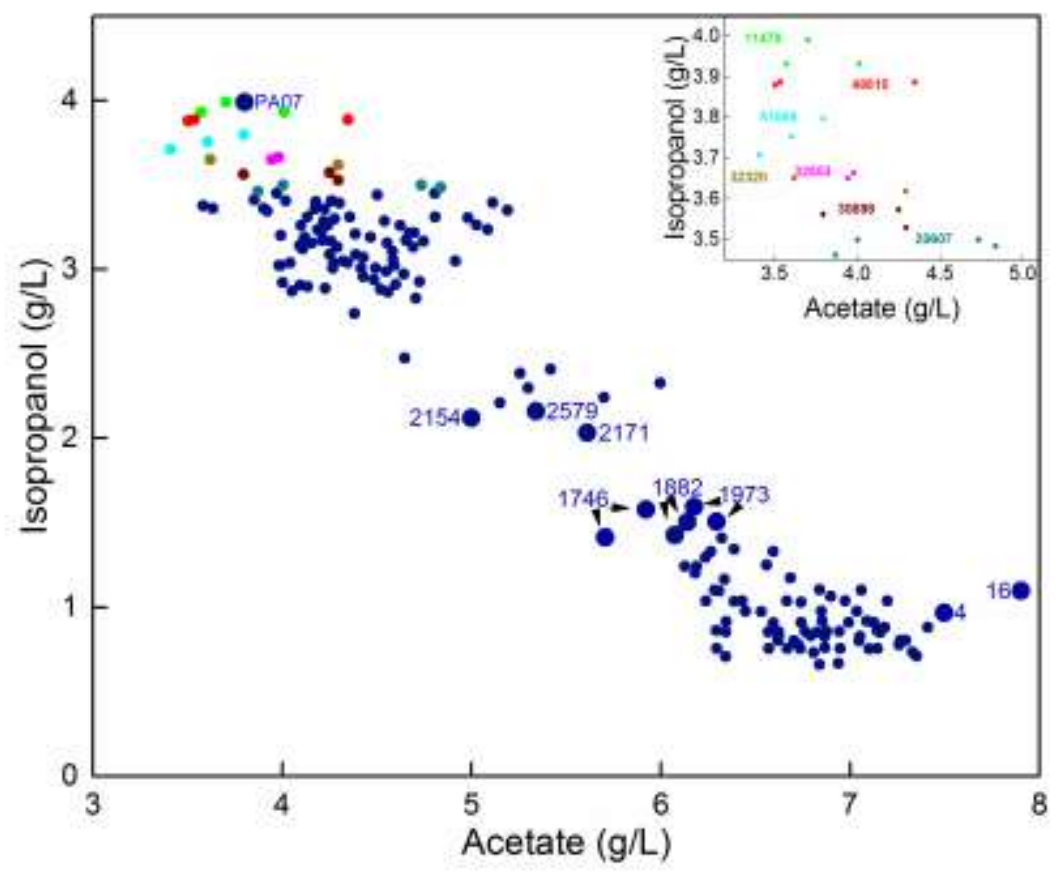

Fig.3A

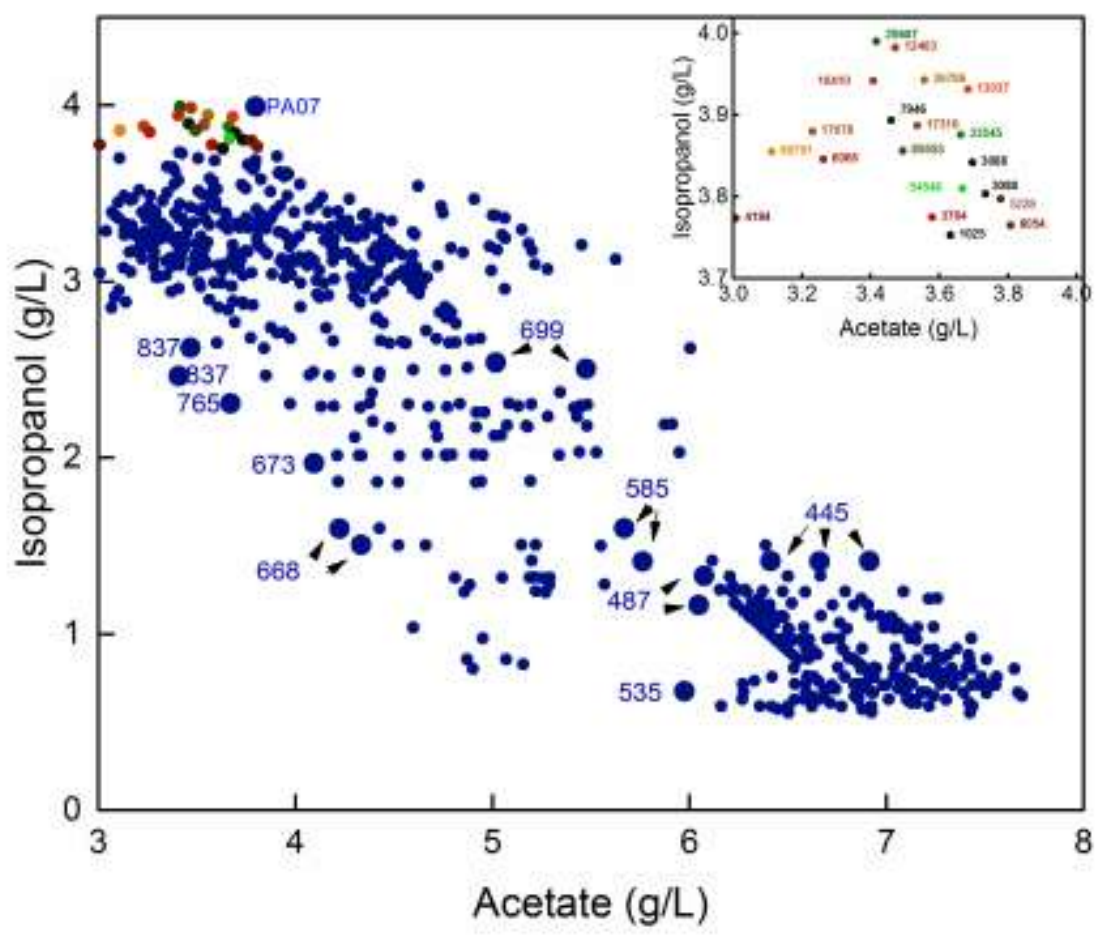

Fig.3B 


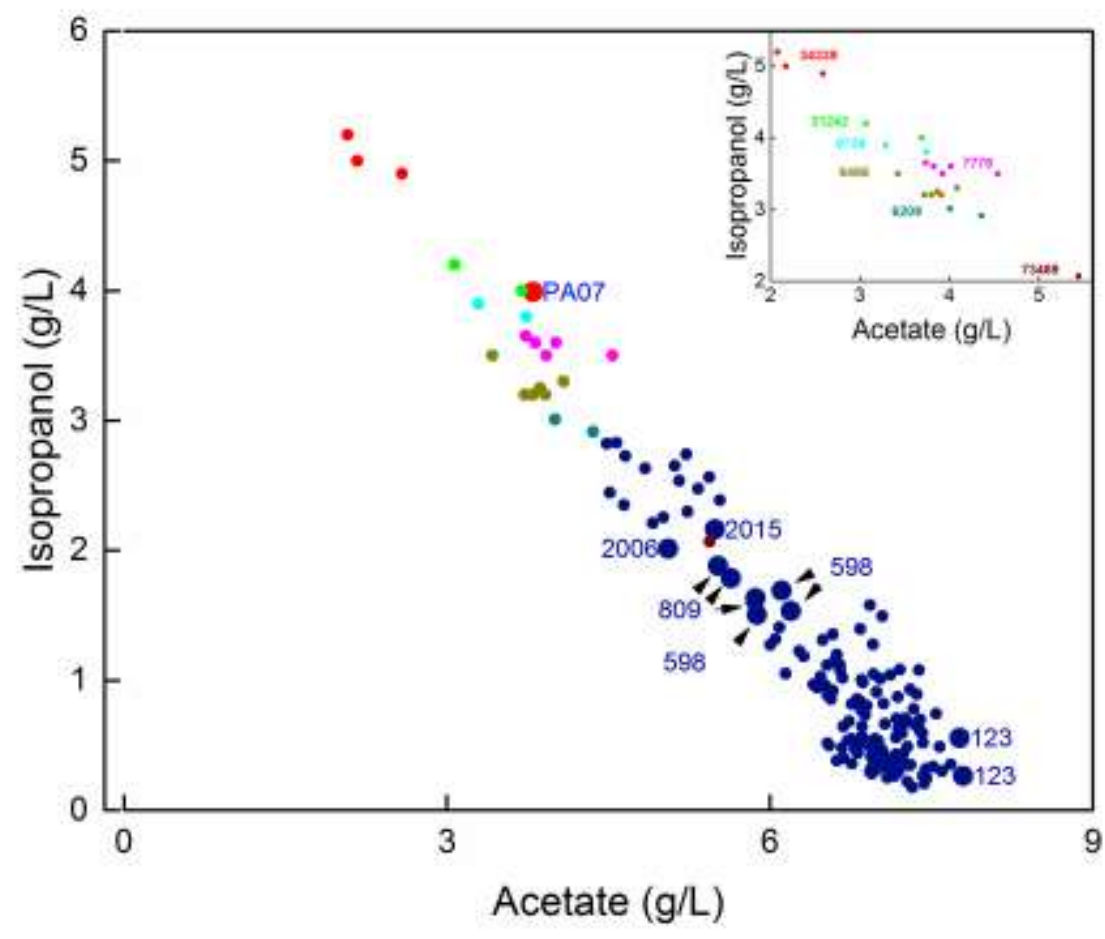

Fig.3C

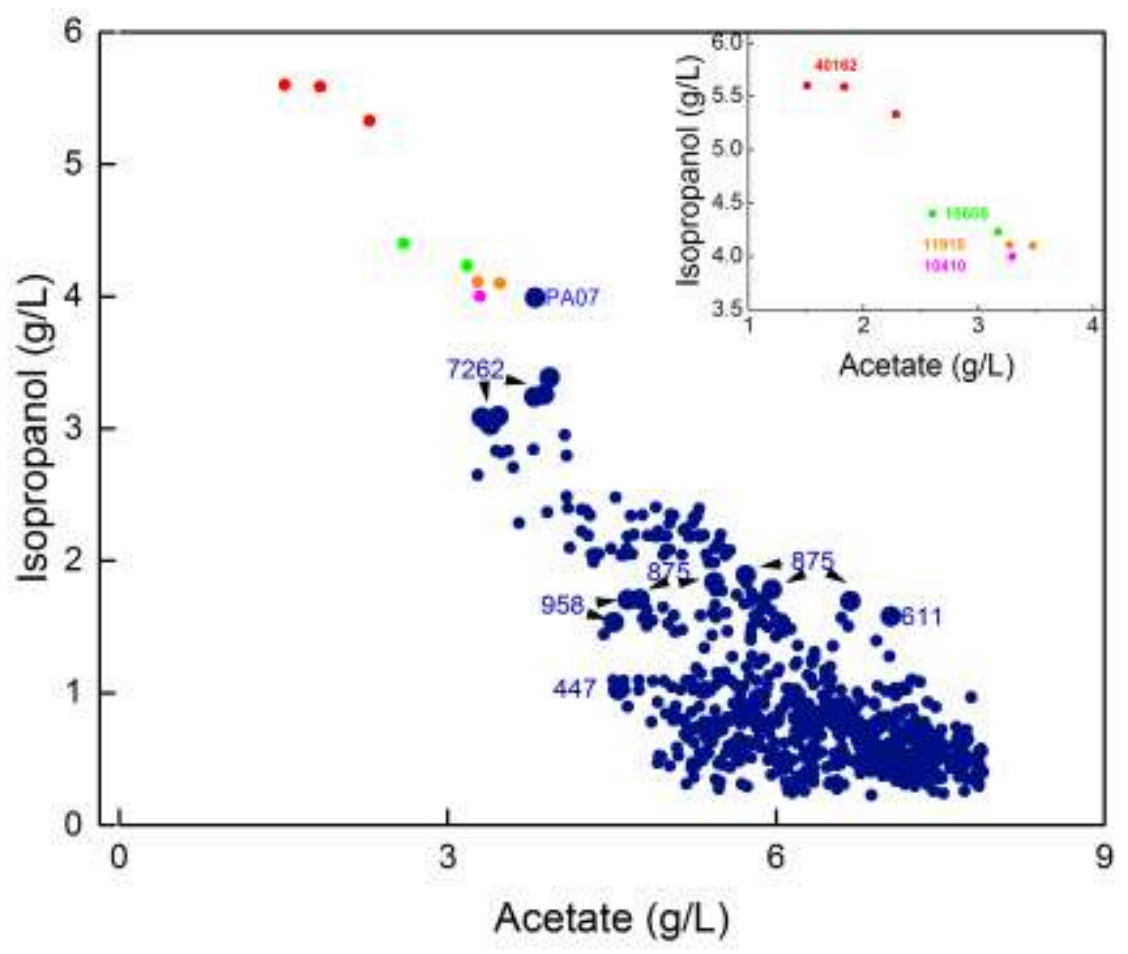

Fig.3D 


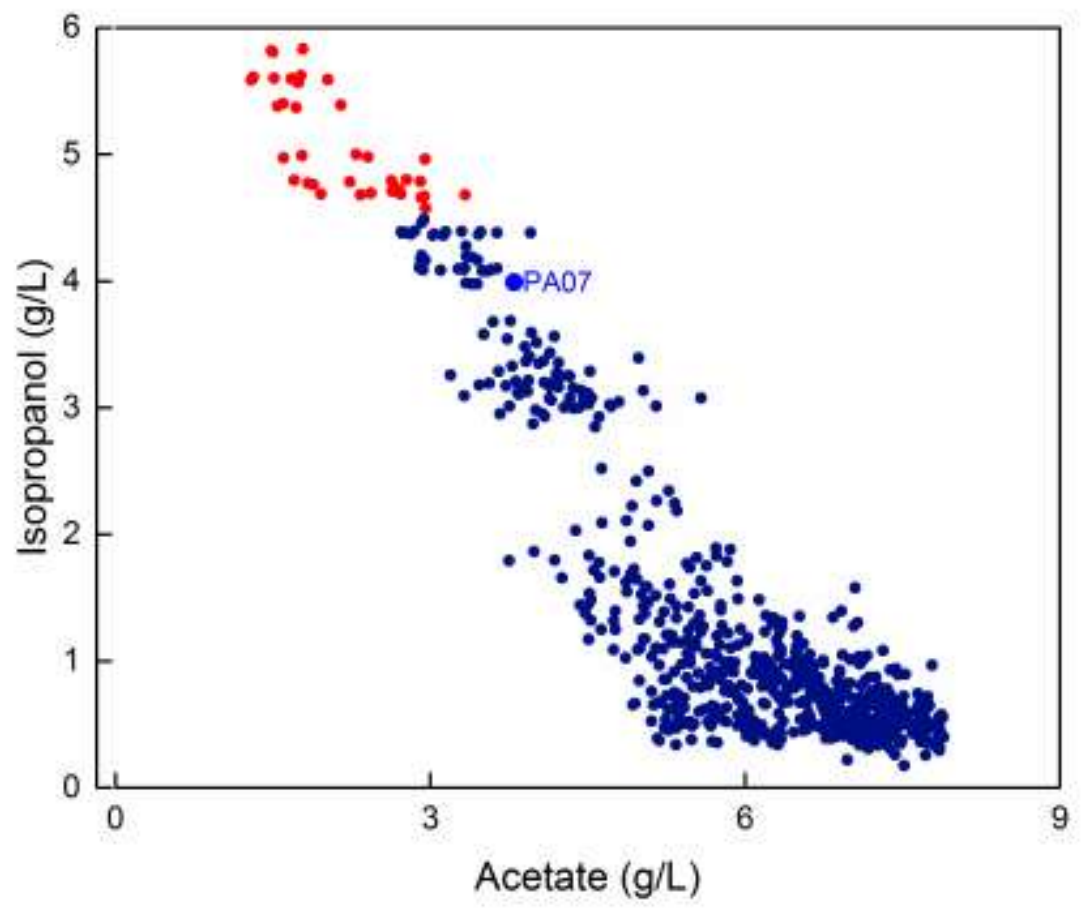

Fig.4A

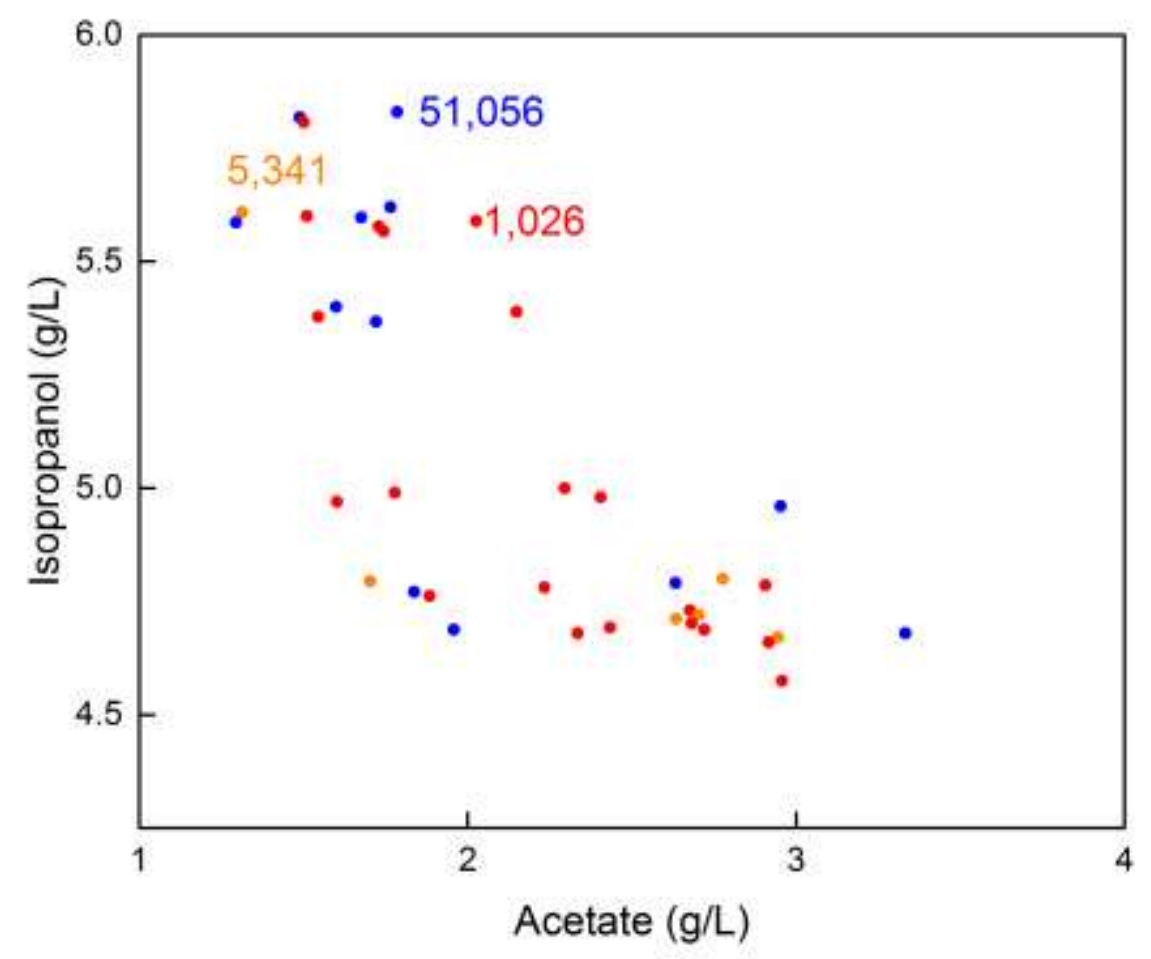

Fig.4B 


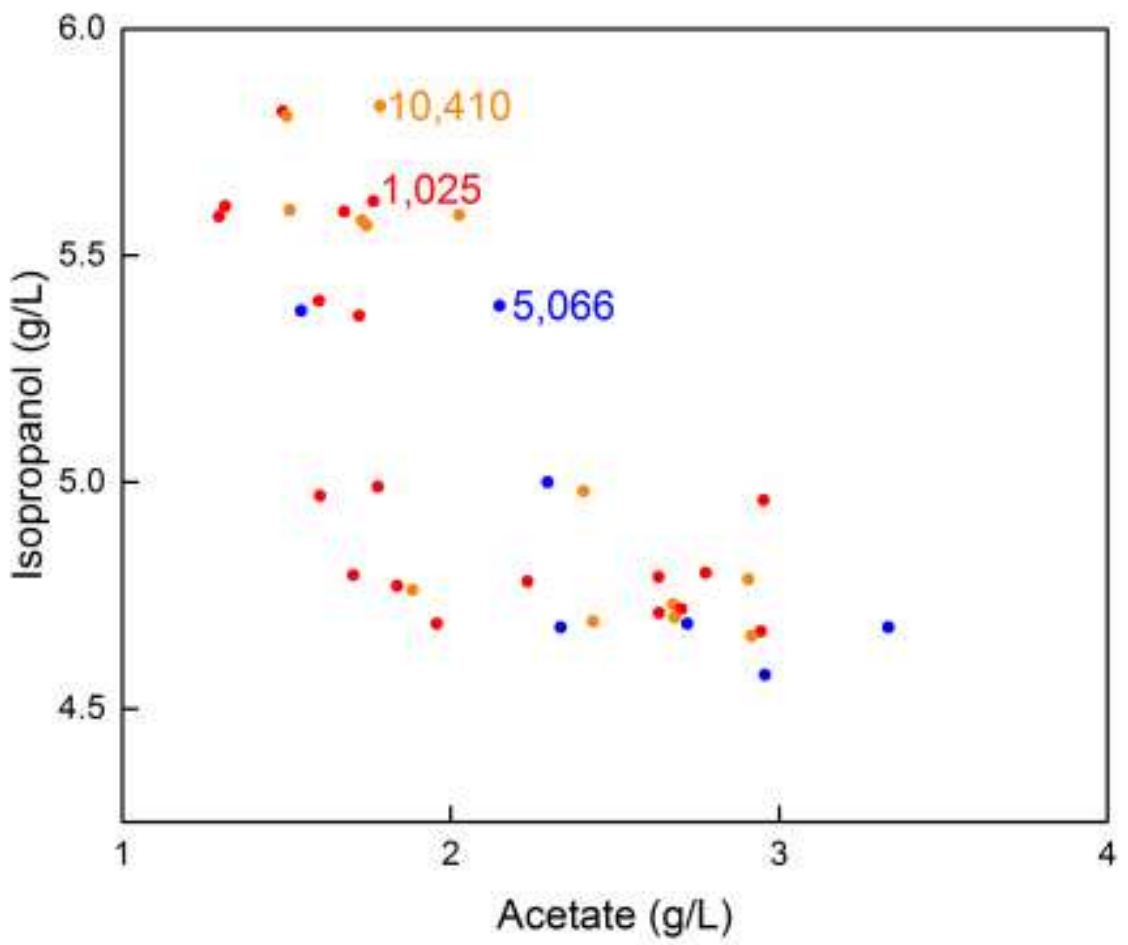

Fig.4C

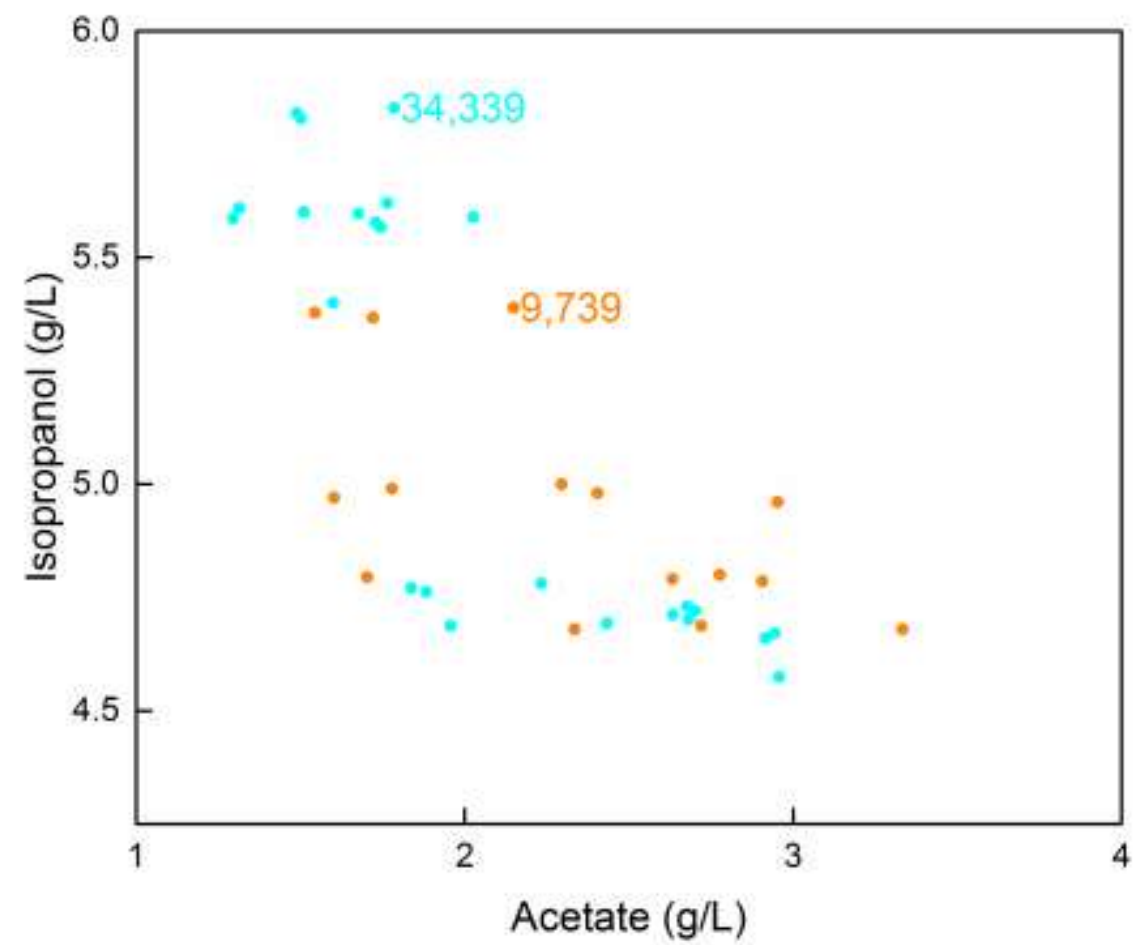

Fig.4D 


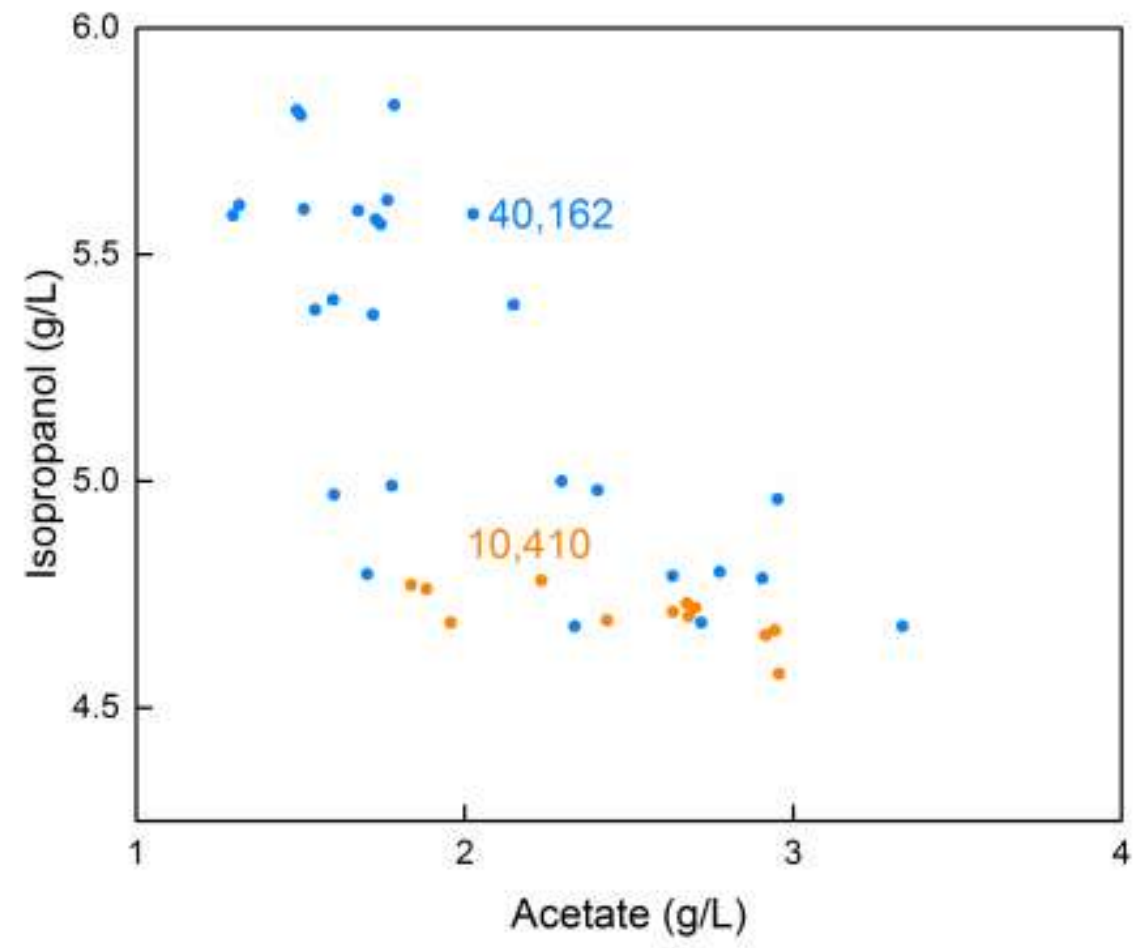

Fig.4E 


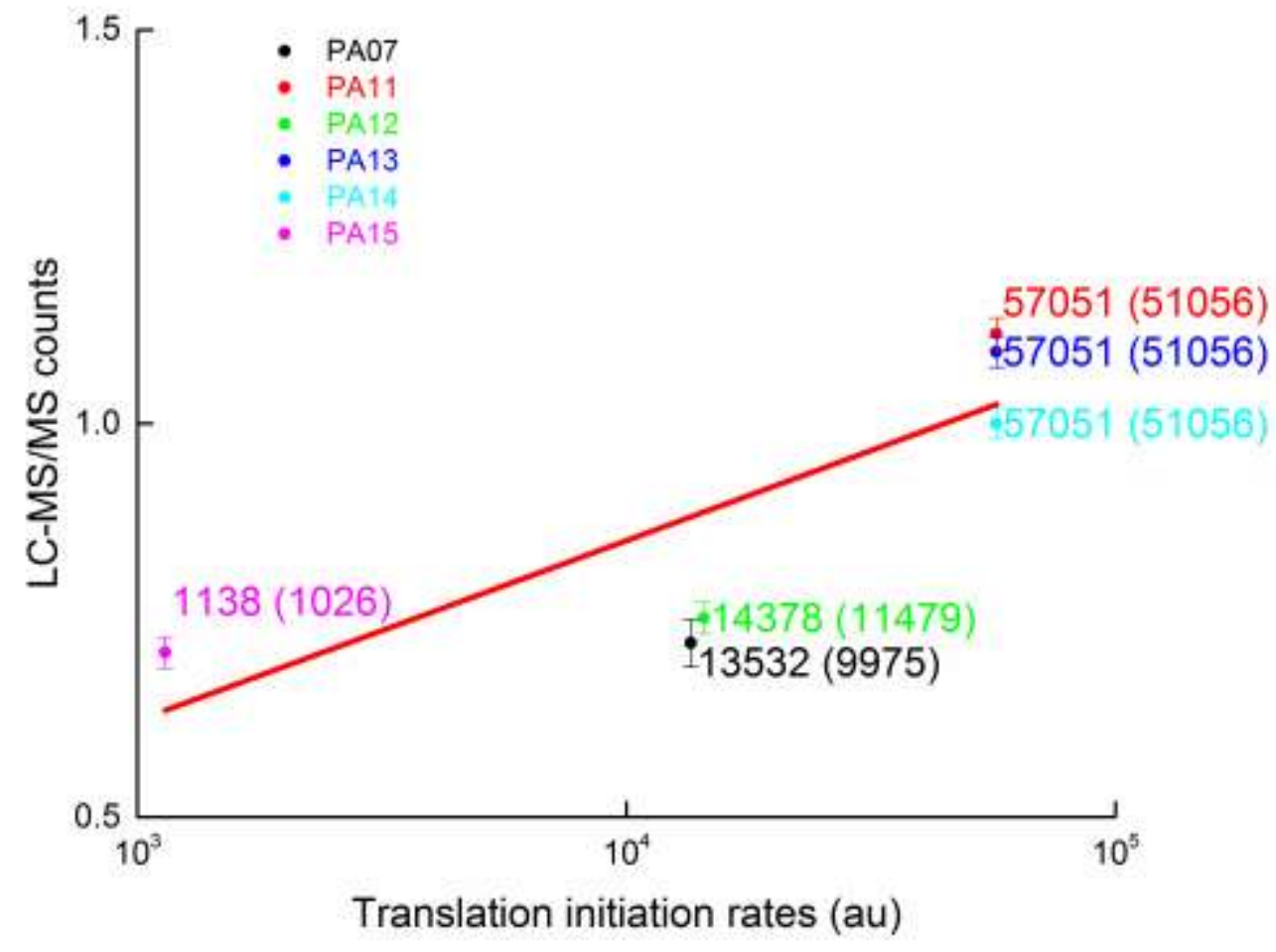

Fig.5A

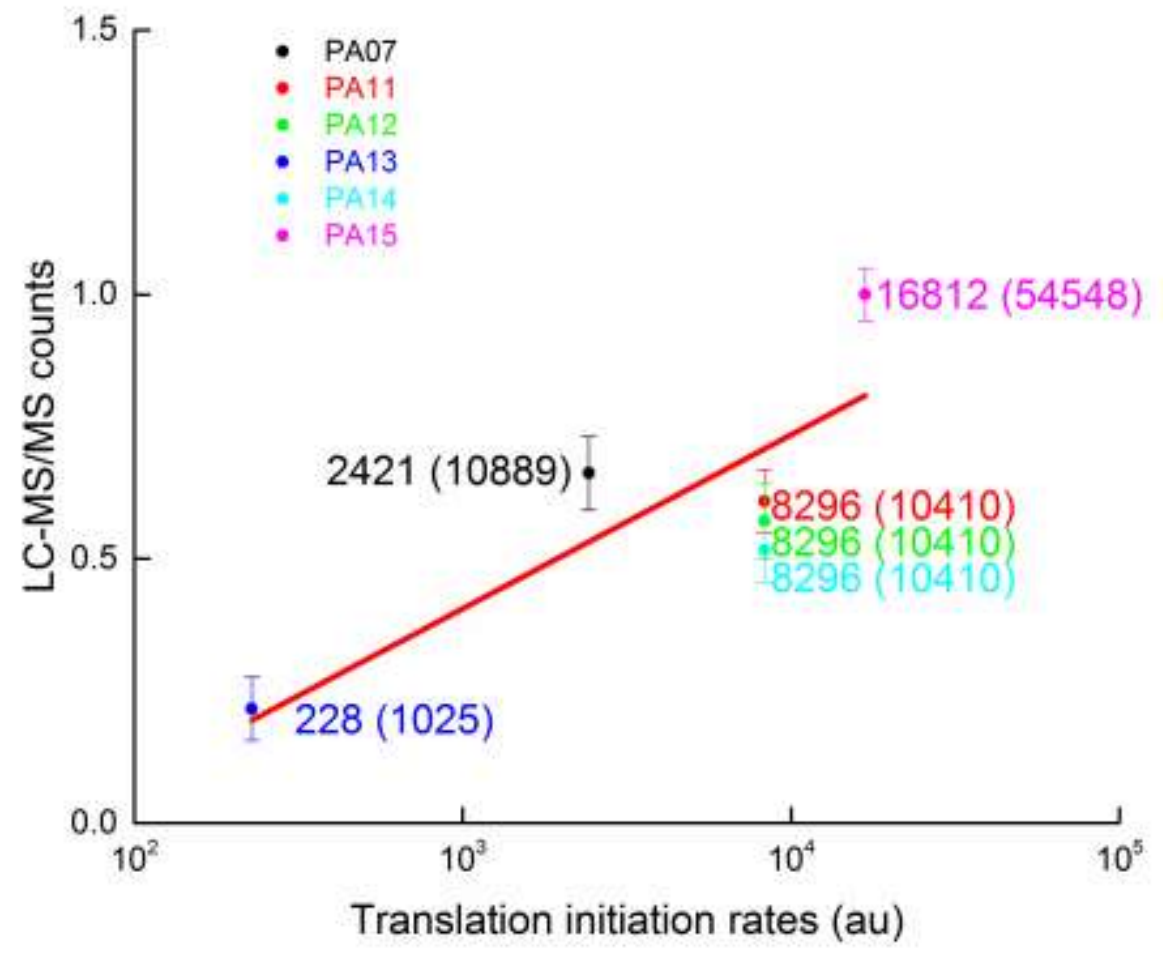

Fig.5B 


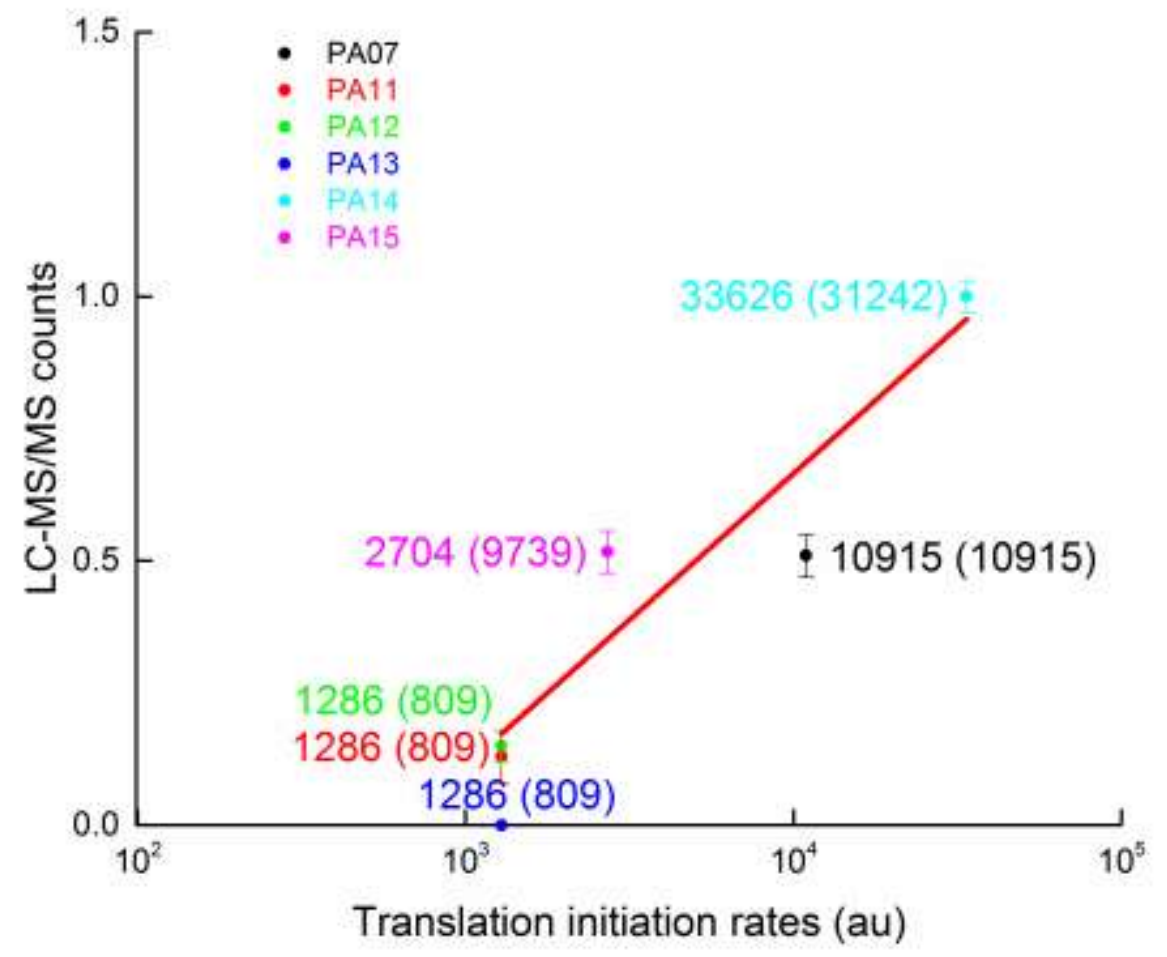

Fig.5C

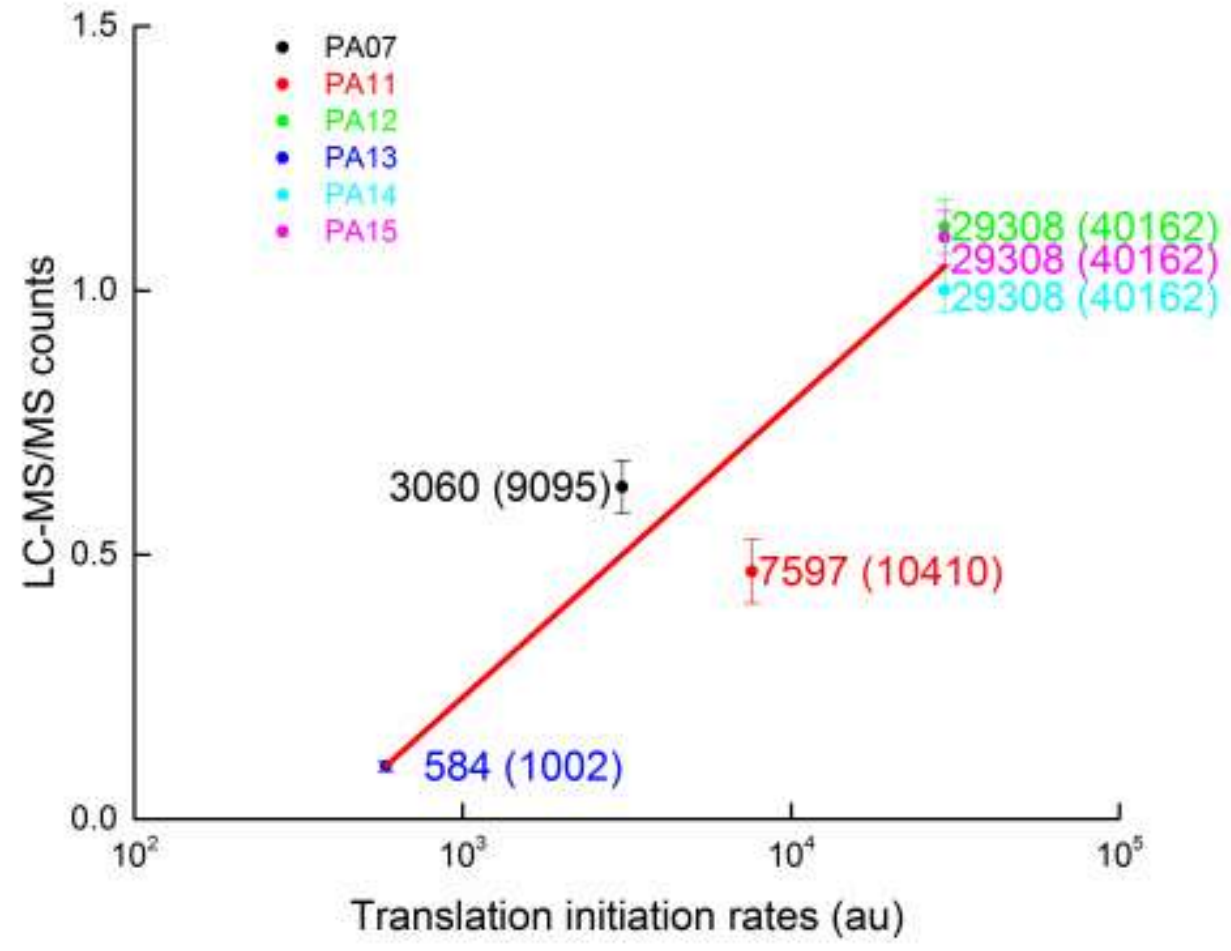

Fig.5D 